NASA/TM-2005-213440

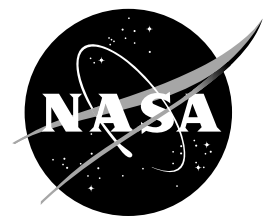

\title{
Local and Total Density Measurements in Ice Shapes
}

Mario Vargas

Glenn Research Center, Cleveland, Ohio

Howard Broughton

Pace Levy, Inc., Westlake, Ohio

James J. Sims

Universal Imaging Corporation, Downingtown, Pennsylvania

Brian Bleeze

ISPA Technology, Inc., Alexandria, Virginia

Vatanna Gaines

Lockheed Martin Aeronautics Company, Marietta, Georgia 
Since its founding, NASA has been dedicated to the advancement of aeronautics and space science. The NASA Scientific and Technical Information (STI) Program Office plays a key part in helping NASA maintain this important role.

The NASA STI Program Office is operated by Langley Research Center, the Lead Center for NASA's scientific and technical information. The NASA STI Program Office provides access to the NASA STI Database, the largest collection of aeronautical and space science STI in the world. The Program Office is also NASA's institutional mechanism for disseminating the results of its research and development activities. These results are published by NASA in the NASA STI Report Series, which includes the following report types:

- TECHNICAL PUBLICATION. Reports of completed research or a major significant phase of research that present the results of NASA programs and include extensive data or theoretical analysis. Includes compilations of significant scientific and technical data and information deemed to be of continuing reference value. NASA's counterpart of peerreviewed formal professional papers but has less stringent limitations on manuscript length and extent of graphic presentations.

- TECHNICAL MEMORANDUM. Scientific and technical findings that are preliminary or of specialized interest, e.g., quick release reports, working papers, and bibliographies that contain minimal annotation. Does not contain extensive analysis.

- CONTRACTOR REPORT. Scientific and technical findings by NASA-sponsored contractors and grantees.
- CONFERENCE PUBLICATION. Collected papers from scientific and technical conferences, symposia, seminars, or other meetings sponsored or cosponsored by NASA.

- SPECIAL PUBLICATION. Scientific, technical, or historical information from NASA programs, projects, and missions, often concerned with subjects having substantial public interest.

- TECHNICAL TRANSLATION. Englishlanguage translations of foreign scientific and technical material pertinent to NASA's mission.

Specialized services that complement the STI Program Office's diverse offerings include creating custom thesauri, building customized databases, organizing and publishing research results ... even providing videos.

For more information about the NASA STI Program Office, see the following:

- Access the NASA STI Program Home Page at http://www.sti.nasa.gov

- E-mail your question via the Internet to help@sti.nasa.gov

- Fax your question to the NASA Access Help Desk at 301-621-0134

- Telephone the NASA Access Help Desk at 301-621-0390

- Write to:

NASA Access Help Desk

NASA Center for AeroSpace Information 7121 Standard Drive

Hanover, MD 21076 
NASA/TM-2005-213440

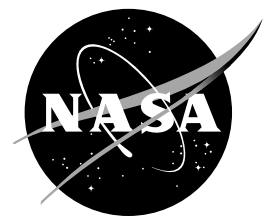

\section{Local and Total Density Measurements in Ice Shapes}

Mario Vargas

Glenn Research Center, Cleveland, Ohio

Howard Broughton

Pace Levy, Inc., Westlake, Ohio

James J. Sims

Universal Imaging Corporation, Downingtown, Pennsylvania

Brian Bleeze

ISPA Technology, Inc., Alexandria, Virginia

Vatanna Gaines

Lockheed Martin Aeronautics Company, Marietta, Georgia

Prepared for the

43rd Aerospace Sciences Meeting and Exhibit

sponsored by the American Institute of Aeronautics and Astronautics Reno, Nevada, January 10-13, 2005

National Aeronautics and

Space Administration

Glenn Research Center 


\section{Acknowledgments}

The authors would like to thank William Sexton, Dave Sheldon, and all the personnel at the Icing Research Tunnel for their help in all phases of the experiment. Special thanks to Clark Hahn for sharing his expertise in x-ray imaging and for his participation in the experiment. We would also like to thank Gary Nolan and Janet Ivancic for their assistance in the digital imaging portions of the experiment, Colin Bidwell for his participation in the initial planning stages of the experiment, and Andrew Reehorst for his help in suggesting a technique to measure local ice densities.

Trade names or manufacturers' names are used in this report for identification only. This usage does not constitute an official endorsement, either expressed or implied, by the National Aeronautics and Space Administration.

Available from

NASA Center for Aerospace Information 7121 Standard Drive

Hanover, MD 21076
National Technical Information Service 5285 Port Royal Road Springfield, VA 22100 


\title{
Local and Total Density Measurements in Ice Shapes
}

\author{
Mario Vargas \\ National Aeronautics and Space Administration \\ Glenn Research Center \\ Cleveland, Ohio 44135 \\ Howard Broughton \\ Pace Levy, Inc. \\ Westlake, Ohio 44148 \\ James J. Sims \\ Universal Imaging Corporation \\ Downingtown, Pennsylvania 19335 \\ Brian Bleeze \\ ISPA Technology, Inc. \\ Alexandria, Virginia 22314 \\ Vatanna Gaines \\ Lockheed Martin Aeronautics Company \\ Marietta, Georgia 30063
}

Preliminary measurements of local and total densities inside ice shapes were obtained from ice shapes grown in the NASA Glenn Icing Research Tunnel for a range of glaze ice, rime ice, and mixed phase ice conditions on a NACA 0012 airfoil at $0^{\circ}$ angle of attack. The ice shapes were removed from the airfoil and a slice of ice $3 \mathrm{~mm}$ thick was obtained using a microtome. The resulting samples were then x-rayed to obtain a micro-radiography, the film was digitized, and image processing techniques were used to extract the local and total density values.

\section{Nomenclature}

Do photographic density of the film after direct exposure to the beam intensity $I_{o}$

$D_{A} \quad$ photographic density of the film after exposure to the transmitted beam intensity through ice region free of voids

$D_{B} \quad$ photographic density of the film after exposure to the transmitted beam intensity through ice sample

$D_{R} \quad$ photographic density of the film after exposure to the transmitted beam intensity through reference piece

E photographic exposure

$\gamma \quad$ slope of the straight line part of the characteristic curve of the photographic emulsion

I beam intensity

$I_{A} \quad$ transmitted intensity of x-ray beam through ice region free of voids

$I_{B} \quad$ transmitted intensity of x-ray beam through ice sample

$I_{O} \quad$ intensity of parallel monochromatic x-ray beam

$m_{B} \quad$ mass contained in volume $X_{A} \cdot 1.1$ in the area of the ice with voids

$\rho_{H} \quad$ density of ice sample

$\rho_{I} \quad$ density of ice in region free of voids

$\sigma \quad$ absorption coefficient

$t \quad$ time of exposure to transmitted intensity

$X \quad$ thickness of material

$X_{A} \quad$ thickness of ice in region free of voids

$X_{B} \quad$ true thickness of ice sample (thickness less voids)

$X_{R} \quad$ thickness of reference piece 


\section{Introduction}

Part of the Aircraft Icing Research Program at NASA Glenn Research Center involves the study and measurement of local and total densities of ice shapes accreted on airfoils. Local density is measured at a given location inside a slice taken from the ice shape. Total density is calculated for the whole slice. Density measurements are needed to study the structure and formation of ice and to obtain fundamental data for the density correlations employed in computer codes that model ice accretion.

This report presents the results of a preliminary experiment carried out in the Icing Research Tunnel (IRT) at NASA Glenn Research Center to measure the local and total densities of ice shapes accreted on a NACA 0012 airfoil mounted vertically at $0^{\circ}$ angle of attack. Density measurements were performed using Prodi's ${ }^{1,2} \mathrm{x}$-ray contact micro-radiography method (of measuring ice density). In the past, measurements of accreted ice density have mainly been performed by using the rotating multi-cylinder technique, ${ }^{3,4}$ but there are difficulties in extending the results to non-rotating bodies such as airfoils. ${ }^{5}$ Prodi's technique, originally applied to hailstones, was extended by taking advantage of modern imaging techniques to measure local and total densities in ice shapes accreted on a NACA 0012 airfoil for a range of icing conditions.

Results are presented for rime, mixed and glaze ice cases. For each ice sample, local densities were measured across different regions of the ice shape. Total densities were also measured for each sample. In addition to the density measurements, image processing techniques were used to visualize air pockets present inside the ice shapes.

\section{Description of Experiment}

\section{A. NASA Glenn Icing Research Tunnel}

Figure 1 shows the Icing Research Tunnel. ${ }^{6}$ The IRT is a closed-loop refrigerated wind tunnel with a test section $6 \mathrm{ft}$ high, $9 \mathrm{ft}$ wide, and $20 \mathrm{ft}$ long. The temperature in the test-section can be controlled from -20 to $+33^{\circ} \mathrm{F}$. Velocities up to $350 \mathrm{mph}$ can be obtained. A spray system allows control of the liquid water content (LWC) between 0.5 to 2.5 grams per cubic meter. The spray nozzles provide droplet median volume diameters (MVD) from 14 to $50 \mu \mathrm{m}$.

\section{B. Test Hardware}

The ice shapes were accreted on a 21-inch chord NACA 0012 airfoil mounted vertically in the test section. The angle-of-attack was set to $0^{\circ}$. An electric heater system consisting of the heater and a power supply allowed the removal of the ice shapes. Figure 2 shows the airfoil in the test section with the electric heater mounted in the center.

A Puffer Hubbard freezer was employed to store the ice shapes. The freezer temperature could be controlled between 0 to $-35^{\circ} \mathrm{F}$. The samples were stored at $-15^{\circ} \mathrm{F}$.

A Zeiss HM 400R sliding microtome with a $\mathrm{C}$ profile steel knife was employed to shave the ice samples to a thickness of $3 \mathrm{~mm}$. The microtome had a fine control from 0 to $60 \mu \mathrm{m}$ which allowed the removal of the ice in small increments from the initial $10 \mathrm{~mm}$ samples cut with the saw. Figure 3 shows the microtome.

A Watkins-Johnson x-ray source type WJ-2308-2 Dmo was used to x-ray the samples. The x-ray unit was mounted on a modified photographic enlarger. The unit had a maximum voltage of $50 \mathrm{kV}$, a maximum output power of 50 Watts and a maximum current of $100 \mathrm{~mA}$. For safety reasons the x-ray device was shielded on three sides with $1 / 4$ inch thick aluminum plates to block scattered rays. Figure 4 shows the $x$-ray source.

\section{Test Conditions}

The test conditions were selected to obtain accretions of rime ice, mixed ice and glaze ice. Test conditions are listed in table 1. Settings for the X-ray source are listed in table 2.

\section{Test Procedure}

Ice shapes were accreted on the NACA 0012 airfoil in the IRT for the icing conditions listed in table 1. Figure 5 shows a schematic of the experimental methodology. An aluminum block with the indented profile of the airfoil geometry was used to make three cuts in the ice in the region of the heater: one at each end of the heater, and another at the midpoint. The heater was activated and the two ice shapes were removed and wrapped in polyvinyl film. The wrapping technique consisted of placing the ice shape in the middle of a piece of polyvinyl film, enveloping the film all around the ice shape, removing as much air as possible by suction, and closing the plastic with a twist-on tie. The ice shapes were stored in the freezer at $-15^{\circ} \mathrm{F}$.

When the needed ice samples were collected, the temperature of the tunnel was lowered to $0{ }^{\circ} \mathrm{F}$, the air flow stopped and the tunnel was used as a cold room. The experimental hardware was moved inside the tunnel and 
allowed to chill until it reached ambient temperature. The ice samples were then removed from the freezer and cut to approximately $10 \mathrm{~mm}$ thickness with a band saw.

To mount the thick slices onto the microtome, an aluminum plate with a trace amount of water frozen on it was placed on a heating pad. When the plate reached the temperature at which the trace quantity of ice was beginning to melt, the plate was removed from the heating pad and the sample placed on it. The plate was immediately placed on a large steel block which acted as a cold sink. The thin liquid film that developed between the ice sample and the plate froze immediately creating a very strong bond. Extreme care was exercised to keep the thin film to a minimum to avoid contamination of the sample.

One side of the sample was microtomed creating a flat surface, then the sample was flipped over and the reverse side microtomed. Since the mounting plate was adjusted to be parallel to the cutting blade, the top and bottom surfaces of the ice sample were also nearly parallel. As the sample neared $3 \mathrm{~mm}$ in thickness, it was measured at eight locations around the perimeter with a depth gage. Microtoming continued until the desired thickness was obtained.

Once the sample was determined to be $3 \mathrm{~mm}$ thick it was removed from the mounting block. The instant that the sample became free from the block it was carefully placed on a sheet of Mylar used to transfer it to the x-ray source. The Watkins-Johnson x-ray source was used to x-ray the sample. Kodak Industrex ready pack II type M x-ray film was used because of its high resolution and sealed packaging. The film was held in place by the film holder (a modified easel), and the sample was placed in contact with the film packet. Prior to exposure the x-ray device was run for several minutes to warm up and reach a stable operational mode. Exposure was determined in the pretest phase of the experiment ensuring the density of the film was within the dynamic range of the film scanner to be used in the image processing, and that the exposure was within the linear part of the characteristic curve of the film emulsion. An input current of $1 \mathrm{~mA}$ and $25 \mathrm{kV}$ exposing the film for 50 seconds produced sufficient density. An exposure of $1 \mathrm{~mA}$ and $20 \mathrm{kV}$ for 35 seconds was used on some samples to reduce vibration effects.

\section{E. Image Processing}

Processing of the film was performed with a Kodak X-Omat radiographic film processor at the recommended time and temperature. The radiographs were scanned with a Leafscan- 45 film scanner at a resolution of 1100 pixels per inch (ppi) and saved to a file. Prior to the experiment the film scanner was tested to evaluate its consistency from scan to scan. It was found that the scanner auto-ranged the output gray values based on the radiography density range. The auto-ranging changed the internal lookup table based on the minimum and maximum intensity value of the pre-scanned image, thereby expanding the dynamic range of the output image. To circumvent the auto-ranging feature a balanced target was pre-scanned, in this case Kodak gray scale, which provided the same minimum and maximum intensity value for each subsequent scan.

Non-uniformities in the x-ray source caused density variations in the film which would affect the localized density measurements. To compensate, a series of flat field images were exposed each day of the experiment. Each flat field image was exposed under the x-ray source without a sample. The flat field images were added to obtain an average flat field image that was digitally subtracted from the sample images.

To accurately add the flat field images and subtract the average from the sample images, registration of the images had to be performed for proper alignment. This was done using two of the four v-shaped registration marks (see fig. 6) which were exposed on each sheet of film to facilitate registration of each image. By having several registration marks any two or all could be used to insure registration accuracy.

Each registration mark was enlarged sufficiently to locate the end point. This was determined accurately by counting the cross-sectional profile of pixels across the registration point and selecting the midpoint pixel, then counting the pixels from the edge of the film to the same midpoint pixel and using these values as a standard measurement for the entire experiment.

To register one image to another, they were superimposed so that each midpoint pixel resided at the same spatial location. The displacement of opposite registration marks was checked to verify proper alignment when scanned. If this varied by more than five pixels the radiograph was realigned in the film holder and rescanned. Other point to point calculations were used to monitor shrinkage and swelling of the film which was found to be negligible.

Once all the radiographs were scanned and registered, the flat field images for that particular day were averaged together into a single flat field image $g(x, y)$

$$
g(x, y)=\frac{1}{N} \sum_{i=1}^{N} f d_{i}(x, y)
$$


where $f d_{i}(x, y)$ is each flat field image. The averaged flat field image was then subtracted from all of the samples images $s(x, y)$ which resulted in the sample image $f s(x, y)$ with corrected intensity values

$$
f s(x, y)=s(x, y)-g(x, y)
$$

Data analysis based on Prodi's methodology was used on image $f s(x, y)$ to obtain the physical densities.

\section{F. Prodi's Methodology}

Correlation of the density (blackness) of the film with the actual physical density of the ice sample is based on Prodi's methodology. The following description of the methodology closely follows Prodi's ${ }^{1,2}$ with some added comments about the assumptions implied in the methodology.

Assume a parallel monochromatic x-ray beam of intensity $I_{o}$ incident on the ice sample and on the thin plate, (see fig. 7). $X_{A}$ is the thickness of the region of the ice free of voids (air bubbles), $\rho_{I}$ the density of the ice in this region, $I_{A}$ the transmitted intensity, and $D_{A}$ the density of the film due to the exposure to the transmitted intensity.

In a region of the ice containing air bubbles, $X_{A}$ is still the thickness of the ice sample (sample assumed to have parallel faces), $X_{B}$ is the true thickness of the material (thickness of the material less voids), $\rho_{H}$ the density of the ice in this region, $I_{B}$ the transmitted intensity, and $D_{B}$ the density of the film due to the exposure to the transmitted intensity.

The ratio of the density of ice in a region containing air bubbles to the density of ice in a region free of air bubbles, can be related to the ratio of the true thickness of the two regions

$$
m_{B}=\rho_{H} X_{A}
$$

where $m_{B}$ is the mass contained in volume $X_{A} \cdot 1.1$ in the region with air bubbles. But $m_{B}$ can be expressed as:

$$
m_{B}=\rho_{I} X_{B}
$$

Then

$$
\rho_{H} X_{A}=\rho_{I} X_{B}
$$

and

$$
\rho_{H} / \rho_{I}=X_{B} / X_{A}
$$

The assumption to obtain Eq. (6) is that the faces of the sample in the region of ice without air bubbles and in the ice with bubbles have the same thickness. A more subtle assumption is that the solid ice between the bubbles in region $\mathrm{B}$ is of the same type as the ice without bubbles in region A. This seemingly trivial fact has special significance in icing where the ice without bubbles is glaze ice and the ice with bubbles is rime or mixed ice. The physics of the formation of the two kinds of ice are different, and there is no a priori reason why the two kinds of ice have to be equal. Another important assumption in the derivation above and in the next step below is that the beam is monochromatic.

The ratio of the true thickness $X_{B} / X_{A}$ can be related to the beam intensity using Lambert's law

$$
I=I o \exp (-\sigma X)
$$

Where $I o$ and $I$ are the incident and transmitted radiation respectively, $\sigma$ is the absorption coefficient of the material, and $X$ is the thickness.

From Eq. (7)

and

$$
X=(1 / \sigma) \ln \left(I_{o} / I\right)
$$

$$
X_{B} / X_{A}=\ln \left(I_{o} / I_{B}\right) / \ln \left(I_{o} / I_{A}\right)
$$

where the coefficient of absorption has been canceled out, assuming the ice is homogeneous wherever there are no bubbles. 
Substitution of Eq. (6) into (9) gives

$$
\rho_{H} / \rho_{I}=\ln \left(I_{o} / I_{B}\right) / \ln \left(I_{o} / I_{A}\right)
$$

Photographic exposure $E$ can be expressed as

$$
E=I \cdot t
$$

where $t$ is the exposure time. The slope of the straight line part of the characteristic curve of the photographic emulsion is defined as

$$
\gamma=D / \log (E)=D / \log (I \cdot t)=D /(\log I+\log t)
$$

where

$$
\log (I)=(D-\gamma \cdot \log (t)) / \gamma
$$

If we operate in the linear region of the film where $\gamma$ is constant, then

$$
\rho_{H} / \rho_{I}=\left[\left(\left(D_{o}-\gamma \cdot \log t\right) / \gamma\right)-\left(\left(D_{B}-\gamma \cdot \log t\right) / \gamma\right)\right] /\left[\left(\left(D_{o}-\gamma \cdot \log t\right) / \gamma\right)-\left(\left(D_{A}-\gamma \cdot \log t\right) / \gamma\right)\right]
$$

Then

$$
\rho_{H} / \rho_{I}=X_{B} / X_{A}=\left(D_{o}-D_{B}\right) /\left(D_{o}-D_{A}\right)
$$

where $D_{o}, D_{A}$, and $D_{B}$ are respectively the measured photographic density in the region clear of the sample, in the region of the sample where the ice is clear of bubbles, and in the region where the ice contains air bubbles.

The local density of the ice sample in a given location, $\rho_{H}$, can be obtained if we know the density at a location within the sample where the ice is clear of bubbles, $\rho_{I}$, and if we measure the film density at three locations: in a region where the ice is clear of bubbles, $D_{A}$, in a region of the film away from the sample, $D_{o}$, and in the region where we want to measure the physical density of the ice, $D_{B}$

$$
\rho_{H}=\rho_{I}\left(D_{o}-D_{B}\right) /\left(D_{o}-D_{A}\right)
$$

\section{Data Analysis}

\section{A. Local Density}

Once the film was scanned and the information was in files, each image was first analyzed using an image processing program (Adobe Photoshop ${ }^{7}$ ) to locate a reference area (about 1 by $2 \mathrm{~mm}$ ) of clear ice where no air pockets were visible and where the thickness was $3 \mathrm{~mm}$. Once this area was located the average gray value for the area was obtained and the gray value was assigned to $D_{A}$ in Eq. (16). The physical density value for this reference area, $\rho_{I}$ in Eq. (16), was assumed to be $0.917 \mathrm{~g} / \mathrm{cm}^{3}$, the typical density of clear ice. A more accurate approach (not used in this experiment) using a separate reference ice piece is discussed in the Appendix. The gray level of the field surrounding the ice sample was expected to be zero due to the flat field subtraction. When the gray levels for the surrounding field were measured they exhibited small deviations from zero. We used $D_{o}$ equal to zero in Eq. (16) and assumed the small deviation from zero to be part of the error in the measurement.

Next, the images were analyzed with a separate image processing application $\left(\operatorname{Sigma~Scan~}^{8}\right)$ to extract intensity profile data. The gray value intensity across various profiles on areas of interest was recorded in a spreadsheet $\left(\right.$ Excel $\left.^{9}\right)$. The gray levels were then converted to local ice densities using Eq. (16), and the results were plotted for each image. 


\section{B. Total Density}

The total density for each image was also calculated in the following way: Adobe Photoshop was used to obtain the mean gray value for the whole image; this value was assigned to $D_{B} . D_{A}, D_{o}$, and $\rho_{I}$ were obtained as in the case of the local densities. Equation (16) was then used to calculate $\rho_{H}$ which was now taken as the total density for the sample.

To visualize the air pockets observed in the samples, edge detection with thresholding was applied to the images using Adobe Photoshop.

\section{Results}

\section{A. Glaze Ice Cases}

To study the density in glaze ice shapes, a baseline case was chosen $\left(\mathrm{V}=150 \mathrm{mph}, \mathrm{LWC}=1.0 \mathrm{~g} / \mathrm{m}^{3}, \mathrm{MVD}=\right.$ $20 \mu \mathrm{m}, \mathrm{T}_{\text {tot }}=28^{\circ} \mathrm{F}, \tau=12$ minutes) and other cases were obtained by changing one or two of the conditions with respect to the base case. The LWC was varied from 0.5 to $1.25 \mathrm{~g} / \mathrm{cm}^{3}$ at $0.25 \mathrm{~g} / \mathrm{cm}^{3}$ increments. Figures 8,9 , and 10 show the results for LWC of $1.0,0.75$, and $1.25 \mathrm{~g} / \mathrm{cm}^{3}$. For each case the local densities were measured along two straight lines labeled red and green. The local densities values tend to remain close to $0.917 \mathrm{~g} / \mathrm{cm}^{3}$, changing dramatically only when there is a void (bubble, air pocket) in the ice. The small deviations observed in the local density values are attributed to the effect of non-uniformities in the x-ray beam since the flat field subtraction technique does not eliminate all the non-uniformities, and also the ice sample has some variations in thickness. Similar results were observed when the velocity was decreased to $100 \mathrm{mph}$ (fig. 11); when the temperature was decreased to $12^{\circ} \mathrm{F}$ while the MVD simultaneously was increased to $30 \mu \mathrm{m}$ (fig. 12); and when the ice accretion time was decreased from 12 to 6 minutes (no figure provided).

\section{B. Mixed Ice Cases}

The case shown in figure $13\left(\mathrm{~V}=150 \mathrm{mph}, \mathrm{LWC}=1.0 \mathrm{~g} / \mathrm{m}^{3}, \mathrm{MVD}=20 \mu \mathrm{m}, \mathrm{T}_{\mathrm{tot}}=12^{\circ} \mathrm{F}, \tau=12\right.$ minutes$)$ was chosen as the base case for the mixed ice cases and other cases were obtained by changing one of the conditions with respect to the base case. The LWC was varied from 0.75 to $1.25 \mathrm{~g} / \mathrm{cm}^{3}$ at $0.25 \mathrm{~g} / \mathrm{cm}^{3}$ increments. Figure 14 shows the result for a LWC of $0.75 \mathrm{~g} / \mathrm{cm}^{3}$. One case was done where the temperature was decreased to $0{ }^{\circ} \mathrm{F}$ while the MVD was simultaneously increased to $30 \mu \mathrm{m}$. This case is presented in figure 15 . The trend in all the mixed ice cases follows the results for the glaze ice cases: the densities measured along the two lines labeled green and red tend to remain near $0.917 \mathrm{~g} / \mathrm{cm}^{3}$ with small deviations due to non-uniformities in the x-ray beam and the thickness of the ice sample, with large changes in the densities due to air pockets in the ice.

\section{Rime Ice Cases}

Figures 16 and 17 present the results for the rime ice cases. The case in figure 16 is for a velocity of $100 \mathrm{mph}$ and a temperature of $0{ }^{\circ} \mathrm{F}$. The case in figure 17 is for a velocity of $200 \mathrm{mph}$ and a temperature of $0{ }^{\circ} \mathrm{F}$. Both cases show the same trend as in the glaze and mixed ice cases with the density values near $0.917 \mathrm{~g} / \mathrm{cm}^{3}$, with small deviations due to non-uniformities in the x-ray beam and the thickness of the ice sample, and with large density variations due to the presence of voids in the ice. There are no major changes in the density when the densities are measured along a line that crosses from one region with a given morphology to another of a different morphology; dramatic changes in the density seem to come only from the presence of air pockets in the ice.

\section{Total Density Measurements}

Table 3 lists the total density measurements. For all cases, the total density measured approaches $0.880 \mathrm{~g} / \mathrm{cm}^{3}$.

\section{Concluding Remarks}

Local and total density measurements have been performed on ice shapes accreted on a NACA 0012 airfoil mounted vertically in the Icing Research Tunnel at $0^{\circ}$ angle of attack. The ice shapes were accreted for a range of icing conditions chosen to produce glaze, mixed and rime ice accretions. The density measurements show that for all cases, the local densities tend to the approximate value of $0.917 \mathrm{~g} / \mathrm{cm}^{3}$ with small deviations due to non-uniformities in the x-ray beam and small variations in the thickness of the sample. Large variations in density were due to air pockets in the ice samples. The density does not change significantly when the morphology of the ice changes, only when there are air pockets present.

All glaze ice shapes studied show the presence of air pockets. The presence of air pockets in ice shapes had also been observed by Olsen and Walker ${ }^{10}$ although the frequency of occurrence was not expected to be this high. Mixed 
and rime ice shapes also showed the presence of air pockets, although they occur less frequently in these cases than in the glaze ice cases. Figure 18 illustrates the air pockets present in glaze, mixed, and rime ice. The observation of air pockets in ice shapes is important when comparing the predictions from ice accretion codes against actual ice shapes, since the presence of the air pockets will require less mass for a given ice accretion shape.

The experiment presented has shown that Prodi's methodology, augmented with modern imaging techniques, allows the measurement of local and total densities in ice shapes accreted on airfoils. Improvements in the accuracy of the technique can be achieved by using a higher quality x-ray source to obtain a better uniformity of the beam, and also improvements in the microtoming technique would allow obtaining an ice sample with more uniform thickness.

\section{Appendix}

In the results presented for this experiment, the reference gray level density $D_{A}$ was obtained in a region of the ice sample that was clear of bubbles and had a thickness close to $3 \mathrm{~mm}$. A better and more accurate approach would have been to use a separate reference piece. A reference piece can be made by freezing very clean water in a medium sized container, the resulting ice will show some bubbles in the middle but will be clear away from the middle zone. The ice can be sawed to a thin slice and pieces of clear ice can be cut to be used as reference pieces. These pieces can be microtomed to the desired thickness.

Although the thickness of the reference piece needs to be known accurately, in principle it does not need to be the same thickness as the ice sample for which local densities are being measured. If a reference piece of thickness $X_{R}$ is x-rayed next to an ice sample of different thickness $X_{A}$, and if $D_{R}$ is the measured photographic density for the reference piece of thickness $X_{R}$, the measured photographic density that would be obtained for a reference piece of thickness $X_{A}$ can be calculated from Eq. (15) in the following way:

$$
X_{R} / X_{A}=\left(D_{o}-D_{R}\right) /\left(D_{o}-D_{A}\right)
$$

where $D_{R}$ is the measured photographic density in the region of the reference piece of thickness $X_{R}, D_{o}$ is the measured photographic density in the region of the film clear of the reference piece, and $D_{A}$ is the calculated measured photographic density in the region of the reference piece if it were of thickness $X_{A}$. Knowing the thickness, and the measured photographic density of a reference piece in a given radiograph, the measured photographic density for any other thickness can be calculated.

If an ice sample has parallel top and bottom surfaces with thickness $X_{A}$, we can calculate local densities using a reference piece of known $X_{R}, D_{R}$. $D_{A}$ is calculated from the reference piece with Eq. (17) and used in Eq. (16) to calculate the local densities.

If the ice sample does not have parallel surfaces, but instead we know the thickness of the ice sample at the locations where the densities are needed, Eq. (17) could be used to calculate the $D_{A}$ at each location and then Eq. (16) can be used to calculate the densities.

Either having an ice sample with parallel top and bottom surfaces or knowing the thickness at the locations where the density measurements are wanted, the densities can be calculated with the help of a reference piece of known thickness and measured photographic density.

\section{References}

${ }^{1}$ Prodi, F., "Measurements of Local Density in Artificial and Natural Hailstones," J. Appl. Meteor., Vol. 9, Dec. 1970, pp. $903-910$.

${ }^{2}$ Prodi, F., "X-ray Images of Hailstones,” J. Appl. Meteor., Vol. 8, June 1969, pp. 458-459.

${ }^{3}$ Jones, K.F., "The Density of Natural Ice Accretions Related to Non-Dimensional Icing Parameters," Q. J. R. Meteorol. Soc., Vol. 116, 1990, pp. 477-496.

${ }^{4}$ Macklin, W.C., "The Density and Structure of Ice Formed by Accretion,” Q. J. R. Meteorol. Soc., Vol. 88, 1962, pp. 30-50.

${ }^{5}$ Rios, M.A., "Icing Simulations Using Jones’ Density Formula for Accreted Ice and LEWICE," AAIA-91-0556.

${ }^{6}$ Soeder, R.H., Sheldon, D.W., Andracchio, C.R., and Ide, R.F., "NASA Lewis Icing Research Tunnel User Manual," NASA TM-107159, June 1996.

${ }^{7}$ Adobe Photoshop 3.0, Adobe Systems Incorporated, 1994.

${ }^{8}$ Sigma Scan/Image 1.20.09, Jandel Scientific Corporation, 1993.

${ }^{9}$ Microsoft Excel 5.0, Microsoft Corporation, 1994.

${ }^{10}$ Olsen, W., and Walker, E., "Experimental Evidence for Modifying the Current Physical Model for Ice Accretion on Aircraft Surfaces,” NASA TM-87184, May 1986.

${ }^{11}$ Broughton, H., Sims, J., and Vargas, M., "Determination of Local Densities in Accreted Ice Samples Using X-Rays and Digital Imaging,” NASA TM-107106, May 1995. 
TABLE 1.-TEST CONDITIONS

\begin{tabular}{|c|c|c|c|c|c|c|c|c|}
\hline $\begin{array}{l}\text { Figure in } \\
\text { the Paper }\end{array}$ & Image & Run \# & $\begin{array}{c}\text { Velocity, } \\
\text { mph }\end{array}$ & $\begin{array}{l}\text { LWC, } \\
\mathrm{g} / \mathrm{m}^{3}\end{array}$ & $\begin{array}{c}\text { MVD, } \\
\mu \mathrm{m}\end{array}$ & $\begin{array}{c}\text { Temperature, } \\
{ }^{\circ} \mathrm{F}\end{array}$ & $\begin{array}{c}\text { Spray Time, } \\
\text { minutes }\end{array}$ & Ice Type \\
\hline & SAG_2cFF.TIF & 061394.01 & 150 & 0.5 & 20 & 28 & 12 & glaze \\
\hline Figure 9 & SAH_2cFF.TIF & 061394.02 & 150 & 0.75 & 20 & 28 & 12 & glaze \\
\hline Figure 8 & SAI_1cFF.TIF & 061394.03 & 150 & 1.0 & 20 & 28 & 12 & glaze \\
\hline \multirow[t]{2}{*}{ Figure 10} & SAO_1cFF.TIF & 061394.01 & 150 & 1.25 & 20 & 28 & 12 & glaze \\
\hline & SAM_1cFF.TIF & 061594.04 & 150 & 1.0 & 20 & 28 & 6 & glaze \\
\hline Figure 11 & SAL_1cFF.TIF & 061594.01 & 100 & 1.0 & 20 & 28 & 12 & glaze \\
\hline Figure 12 & SR_1cFF.TIF & 062194.01 & 150 & 1.0 & 30 & 12 & 12 & glaze \\
\hline \multirow[t]{2}{*}{ Figure 13} & SAJ_1cFF.TIF & 061394.06 & 150 & 1.0 & 20 & 12 & 12 & mixed \\
\hline & SL_1cFF.TIF & 061594.09 & 150 & 1.0 & 20 & 12 & 12 & mixed \\
\hline \multirow[t]{3}{*}{ Figure 14} & SO_1cFF.TIF & 061594.08 & 150 & 0.75 & 20 & 12 & 12 & mixed \\
\hline & SN_2cFF.TIF & 061594.10 & 150 & 1.25 & 20 & 12 & 12 & mixed \\
\hline & SS_1cFF.TIF & 062194.02 & 150 & 1.0 & 20 & 12 & 6 & mixed \\
\hline Figure 15 & SZ_1cFF.TIF & 062194.09 & 150 & 1.0 & 30 & 0 & 12 & mixed \\
\hline Figure 16 & SAA_2cFF.TIF & 062194.10 & 100 & 1.0 & 20 & 0 & 12 & rime \\
\hline Figure 17 & SAB_1cFF.TIF & 062194.11 & 200 & 1.0 & 20 & 0 & 12 & rime \\
\hline
\end{tabular}


TABLE 2.-X-RAY SETTINGS

[Setting II was used on some samples to reduce vibration effects.]

\begin{tabular}{|c|c|c|}
\cline { 2 - 3 } \multicolumn{1}{c|}{} & SETTING I & SETTING II \\
\hline Voltage & $25 \mathrm{kV}$ & $30 \mathrm{kV}$ \\
\hline Current & $100 \mathrm{~mA}$ & $100 \mathrm{~mA}$ \\
\hline Distance from X-Ray source to ice sample & $2 \mathrm{ft}$ & $2 \mathrm{ft}$ \\
\hline Time of Exposure & 50 seconds & 35 seconds \\
\hline
\end{tabular}

TABLE 3.-TOTAL DENSITY

\begin{tabular}{|c|c|c|c|c|c|}
\hline Image & $\begin{array}{c}\text { Average Gray } \\
\text { Value }\end{array}$ & $\begin{array}{c}\text { Reference Gray } \\
\text { Value }\end{array}$ & $\begin{array}{l}\text { Total Density, } \\
\qquad \mathrm{g} / \mathrm{cm}^{3}\end{array}$ & $\begin{array}{c}\text { Approximate } \\
\text { Measured } \\
\text { Thickness, } \\
\text { inches }\end{array}$ & Ice Type \\
\hline SAG_2cFF.TIF & 152.68 & 156.47 & 0.895 & 0.118 & glaze \\
\hline SAH_2cFF.TIF & 142.95 & 150.73 & 0.870 & 0.118 & glaze \\
\hline SAI_1cFF.TIF & 146.55 & 154.41 & 0.870 & 0.118 & glaze \\
\hline SAO_1cFF.TIF & 147.51 & 157.90 & 0.857 & 0.121 & glaze \\
\hline SAM_1cFF.TIF & 145.91 & 148.01 & 0.904 & 0.118 & glaze \\
\hline SAL_1cFF.TIF & 140.78 & 148.69 & 0.868 & 0.117 & glaze \\
\hline SR_1cFF.TIF & 147.15 & 156.53 & 0.862 & 0.118 & glaze \\
\hline SAJ_1cFF.TIF & 149.81 & 158.83 & 0.865 & 0.119 & mixed \\
\hline SL_1cFF.TIF & 135.38 & 142.11 & 0.874 & 0.116 & mixed \\
\hline SO_1cFF.TIF & 136.81 & 139.22 & 0.901 & 0.109 & mixed \\
\hline SN_2cFF.TIF & 143.01 & 147.43 & 0.890 & 0.118 & mixed \\
\hline SS_1cFF.TIF & 150.25 & 155.00 & 0.889 & 0.118 & mixed \\
\hline SZ_1cFF.TIF & 151.60 & 154.56 & 0.899 & 0.118 & mixed \\
\hline SAB_1cFF.TIF & 145.89 & 153.22 & 0.873 & 0.113 & rime \\
\hline
\end{tabular}




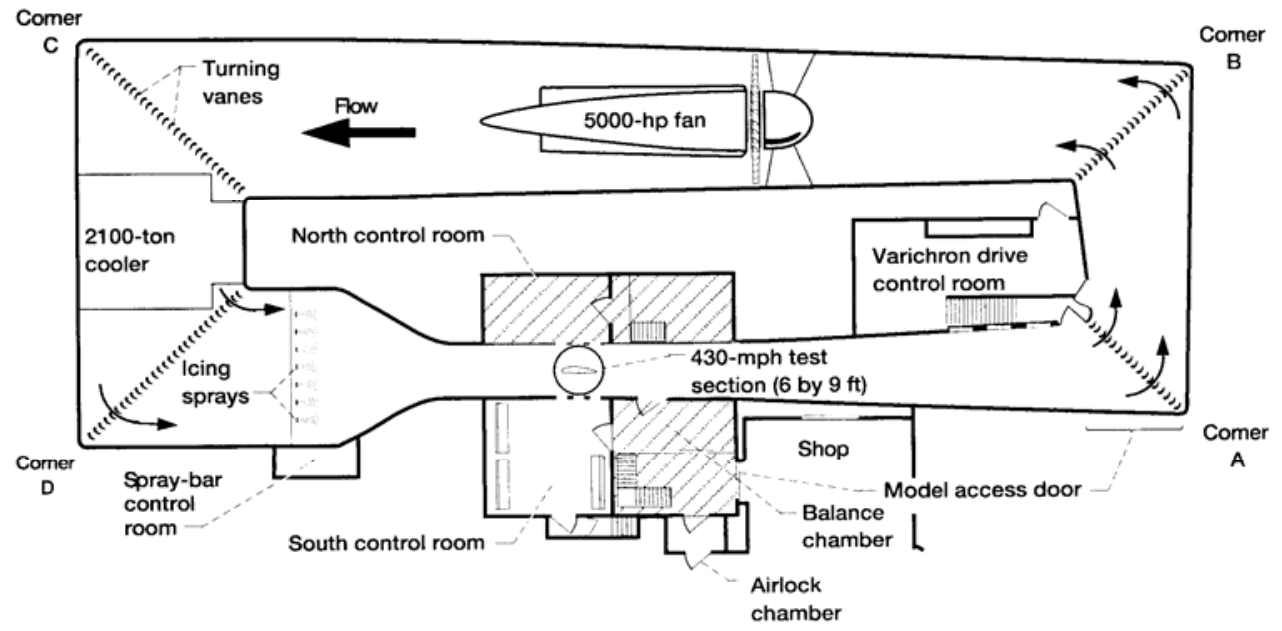

Figure 1.-NASA Glenn Icing Research Tunnel, plan view.

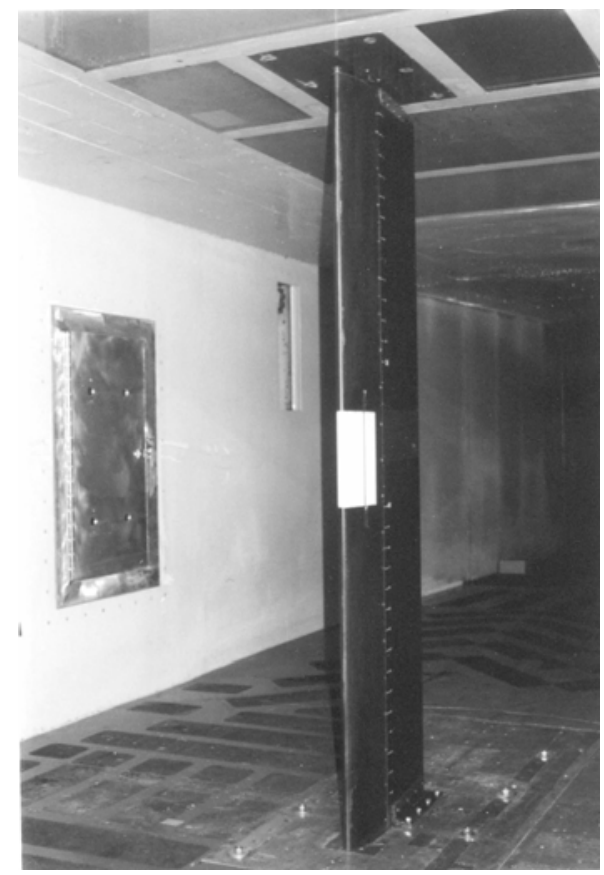

Figure 2.-NACA 0012 airfoil at $0^{\circ}$ angle of attack, positioned for testing in the IRT. The white patch in the center of the airfoil is the electric heater. 


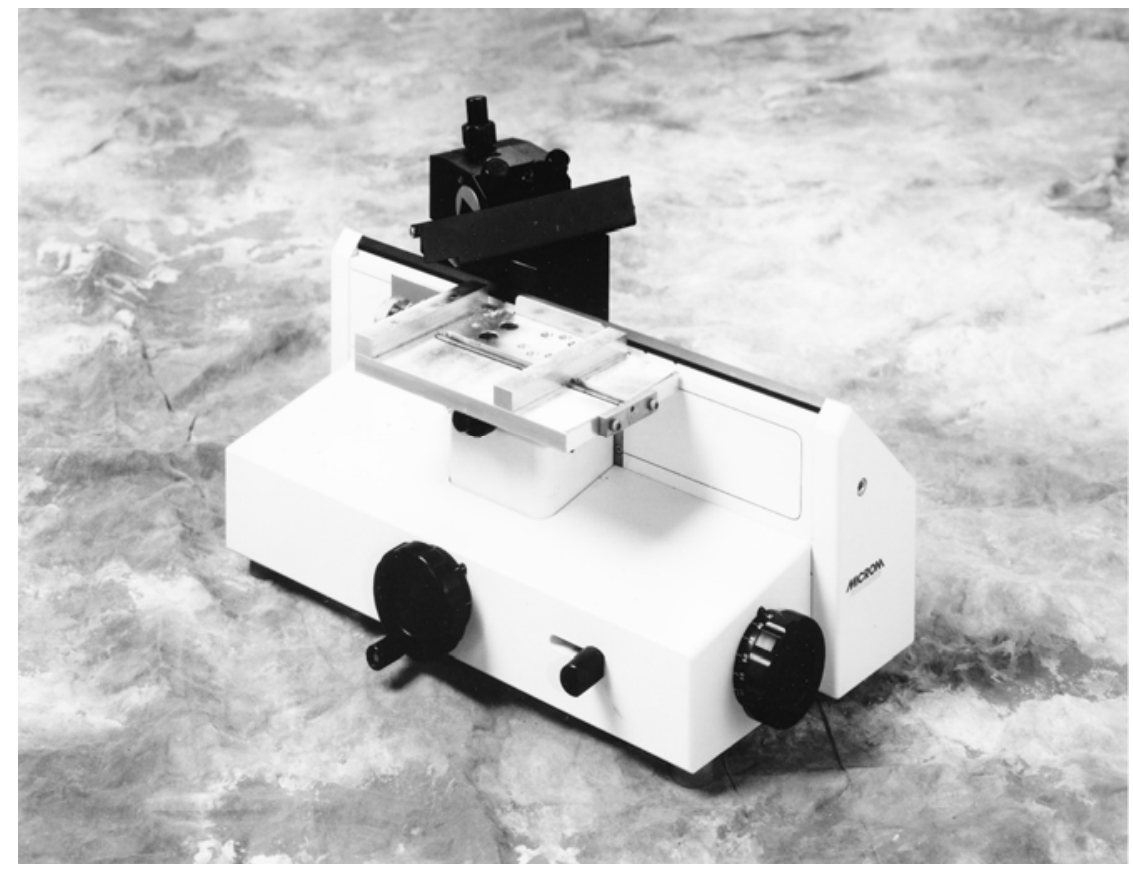

Figure 3.--Sliding microtome.

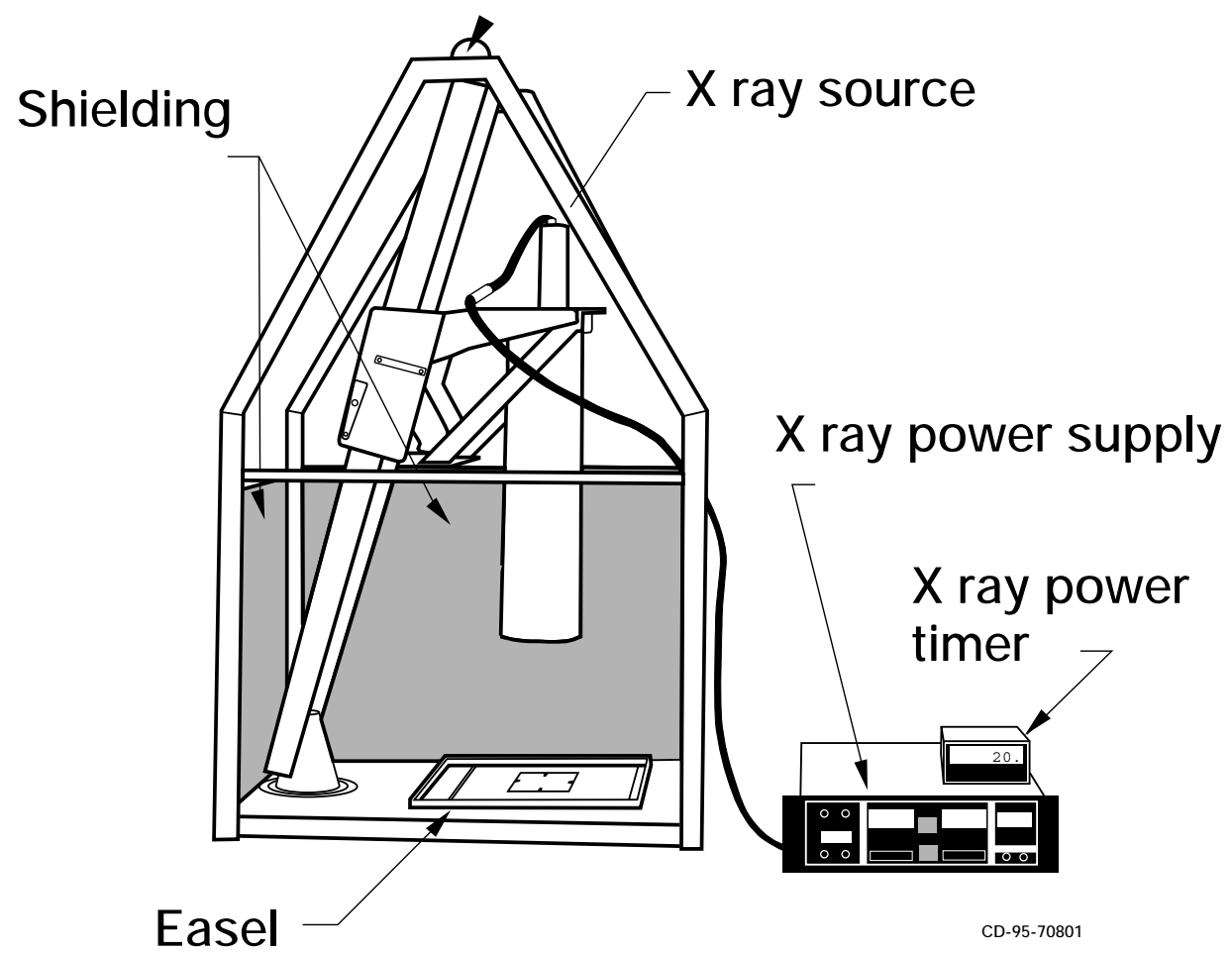

Figure 4.-X-ray device. 

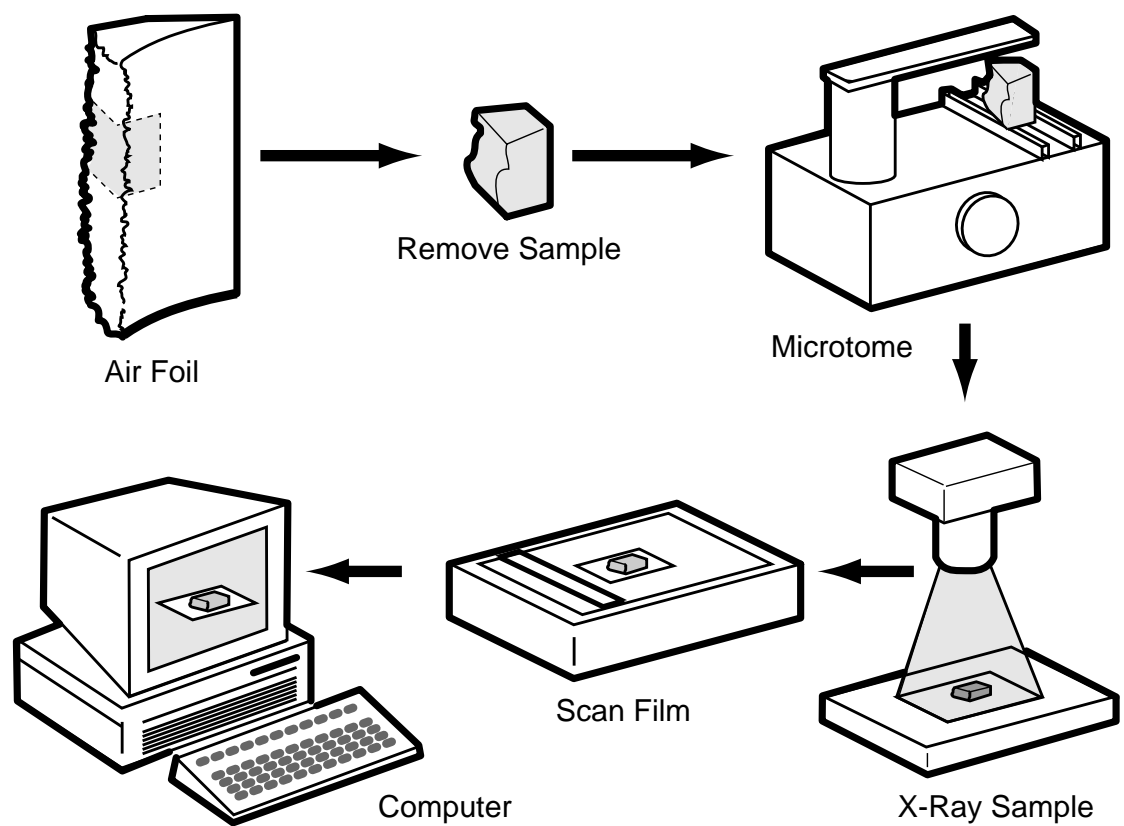

Figure 5.-Methodology of experiment.

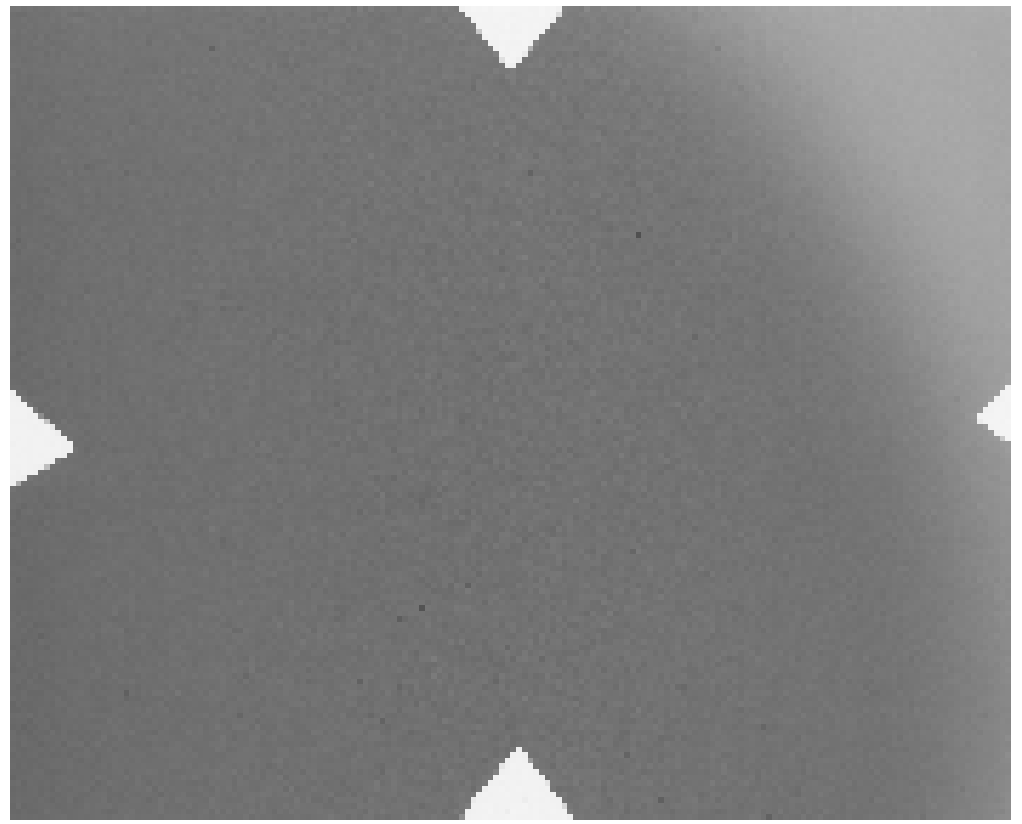

Figure 6.-Flat field image with triangular registration marks used to verify alignment when superimposing flat field images and sample images. 


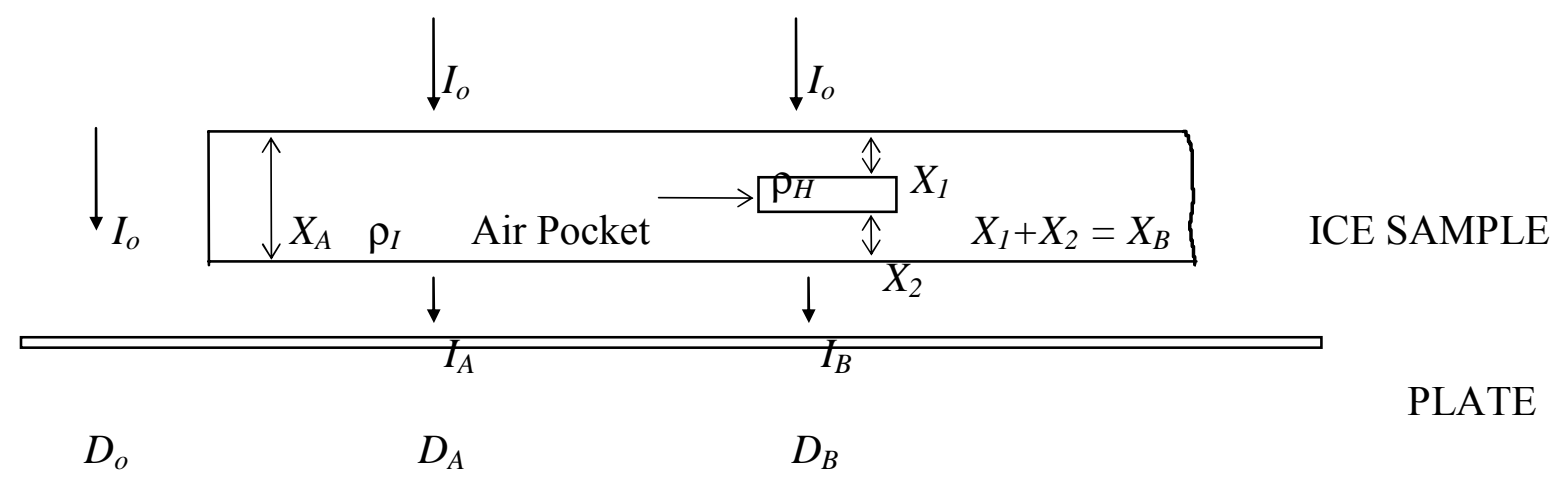

Figure 7.- Nomenclature used to describe the absorption of a parallel monochromatic x-ray beam of intensity Io incident on the ice sample and on the plate. Adapted from $\operatorname{Prodi}^{1}(1970)$ 

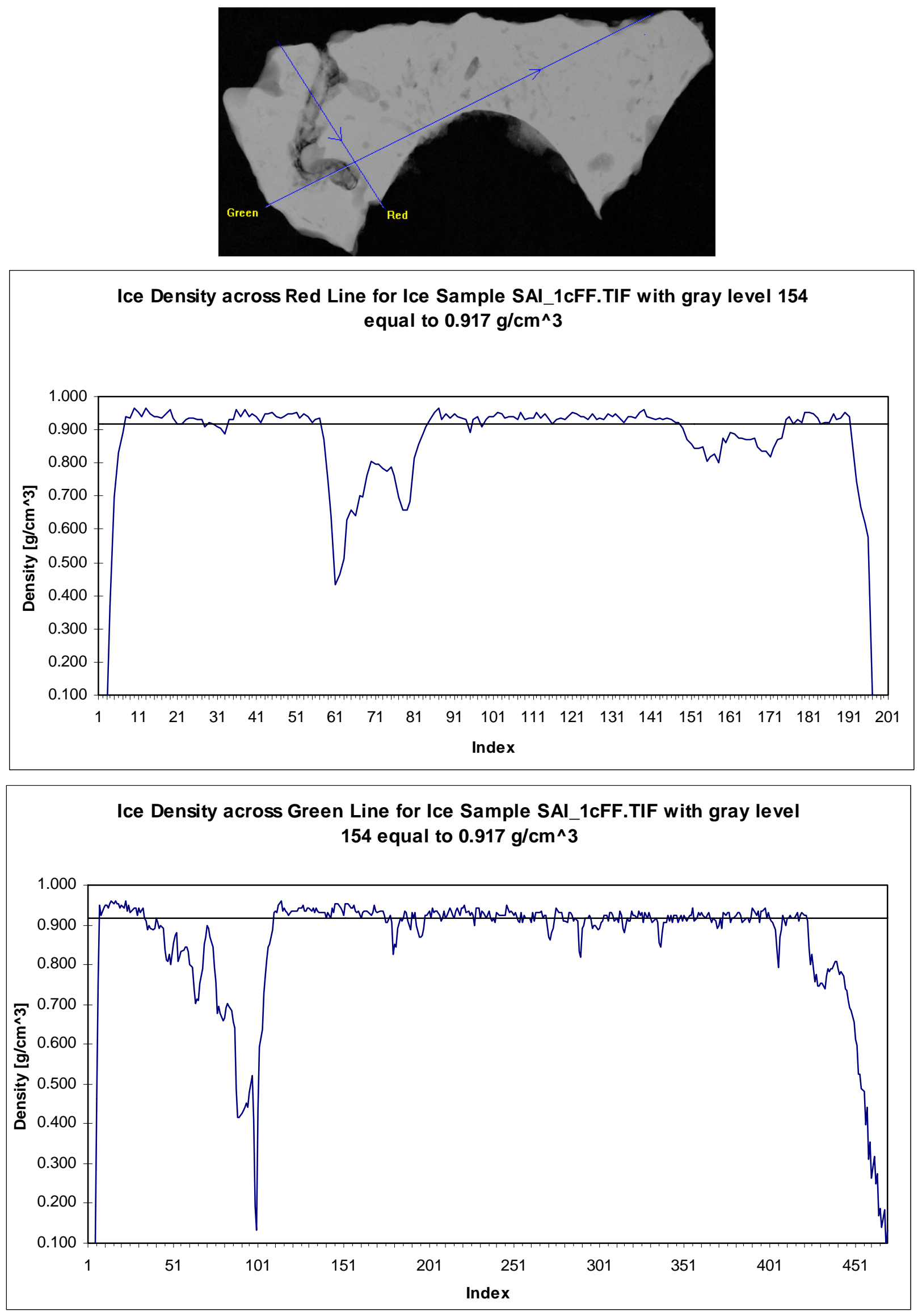

Figure 8. - Sample SAI_1cFF.TIF for glaze ice case. V $=150 \mathrm{mph}, \mathrm{LWC}=1.0 \mathrm{~g} / \mathrm{m}^{3}, \mathrm{MVD}=20 \mu \mathrm{m}, \mathrm{T}_{\text {tot }}=$ $28^{\circ} \mathrm{F}, \tau=12$ minutes. 

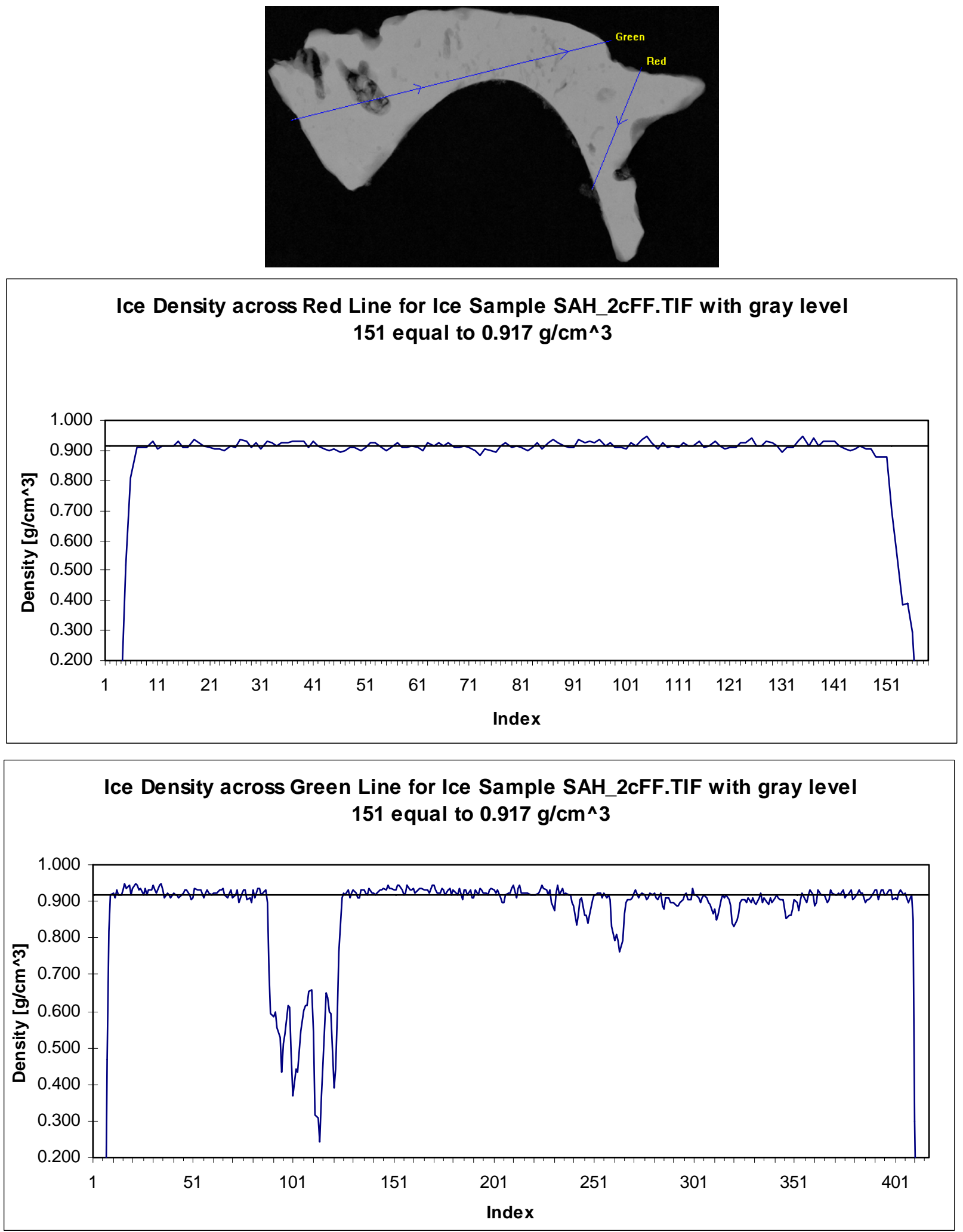

Figure 9.-Sample SAH_2cFF.TIF for glaze ice case. V $=150 \mathrm{mph}, \mathrm{LWC}=0.75 \mathrm{~g} / \mathrm{m}^{3}, \mathrm{MVD}=20 \mu \mathrm{m}$, $\mathrm{T}_{\text {tot }}=28^{\circ} \mathrm{F}, \tau=12$ minutes. 

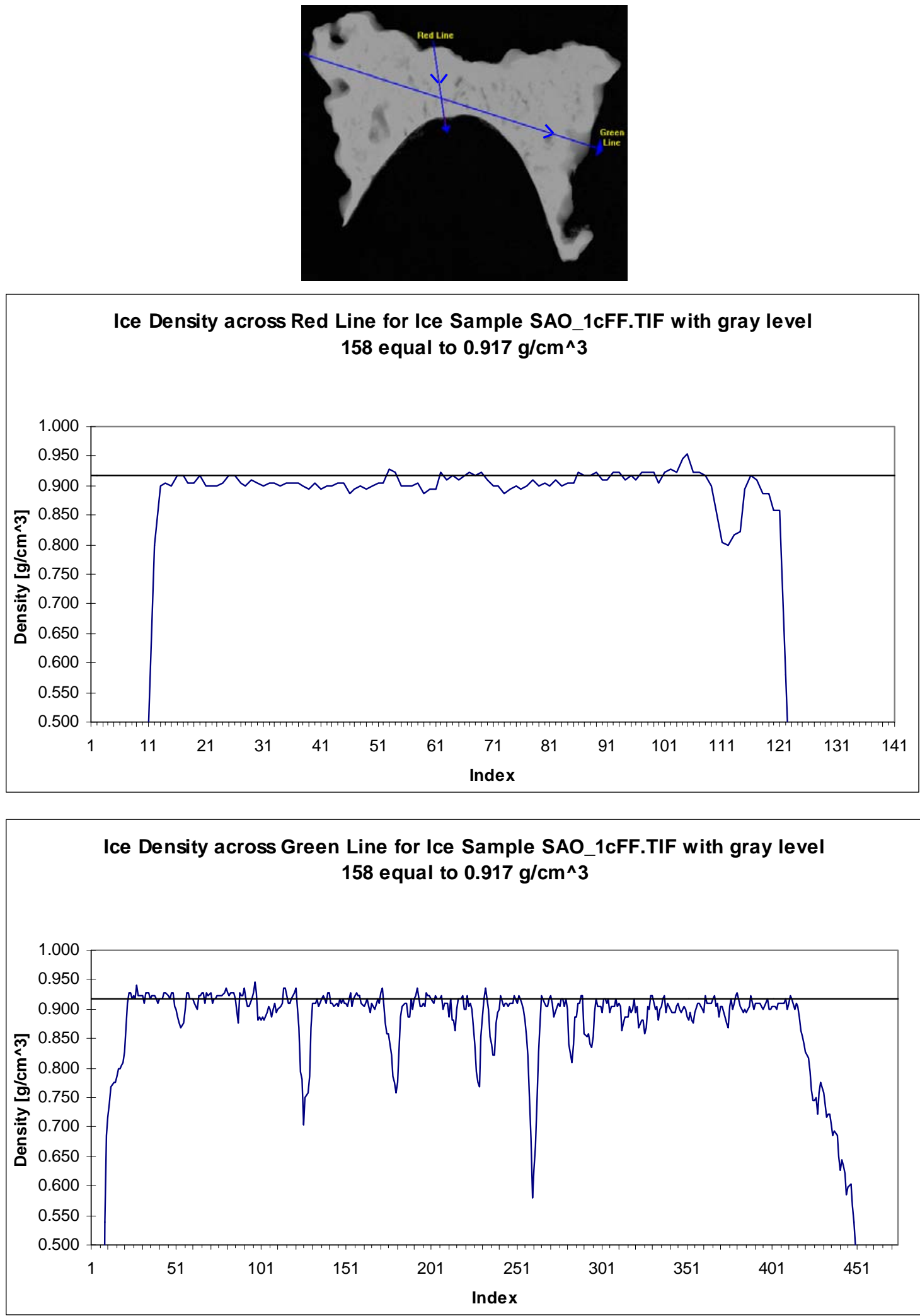

Figure 10.-Sample SAO_1cFF.TIF for glaze ice case. V $=150 \mathrm{mph}, \mathrm{LWC}=1.25 \mathrm{~g} / \mathrm{m}^{3}, \mathrm{MVD}=$ $20 \mu \mathrm{m}, \mathrm{T}_{\text {tot }}=28^{\circ} \mathrm{F}, \tau=12$ minutes. 

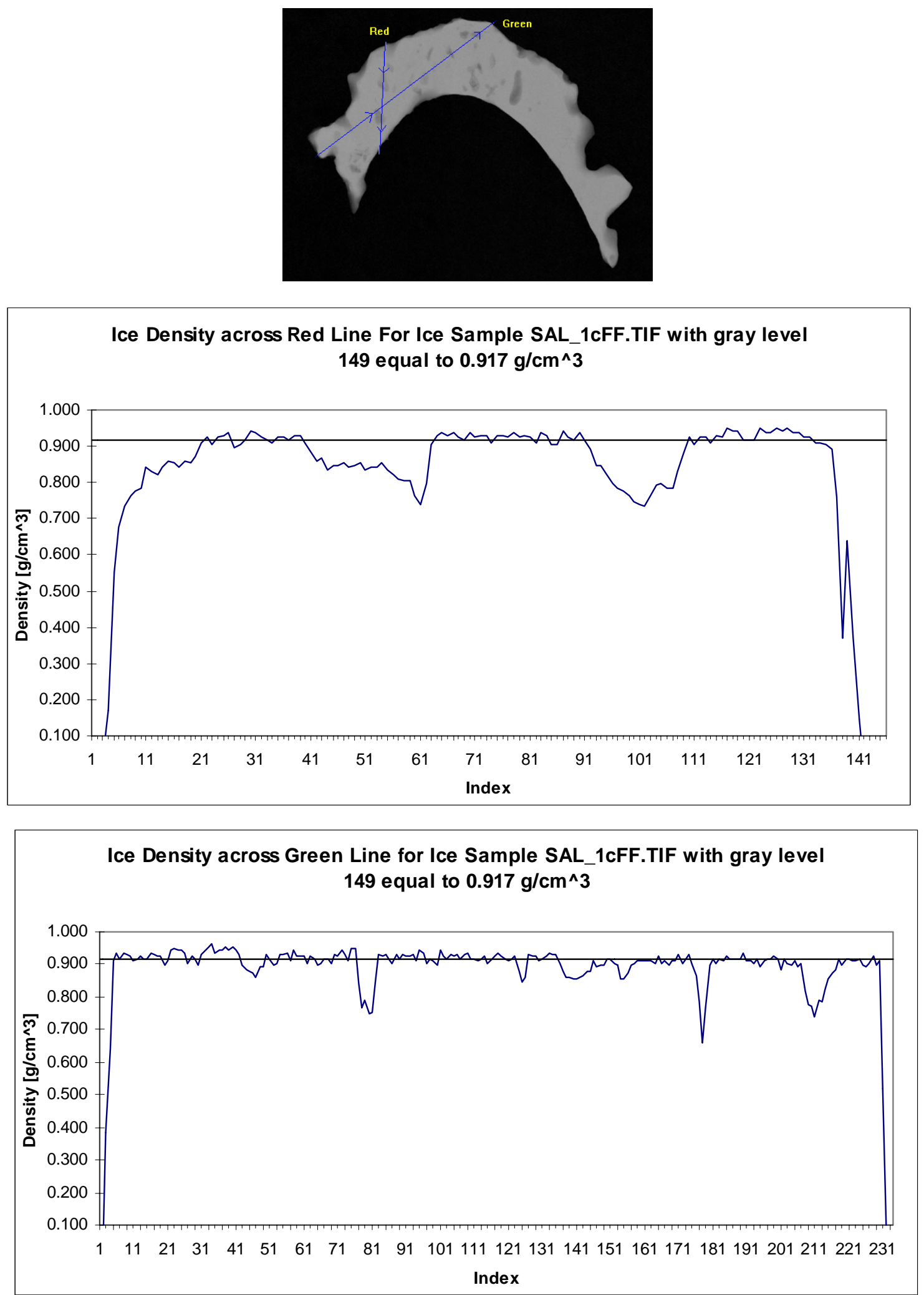

Figure 11._-Sample SAL_1cFF.TIF for glaze ice case. V $=100 \mathrm{mph}, \mathrm{LWC}=1.0 \mathrm{~g} / \mathrm{m}^{3}, \mathrm{MVD}=$ $20 \mu \mathrm{m}, \mathrm{T}_{\text {tot }}=28^{\circ} \mathrm{F}, \tau=12$ minutes. 

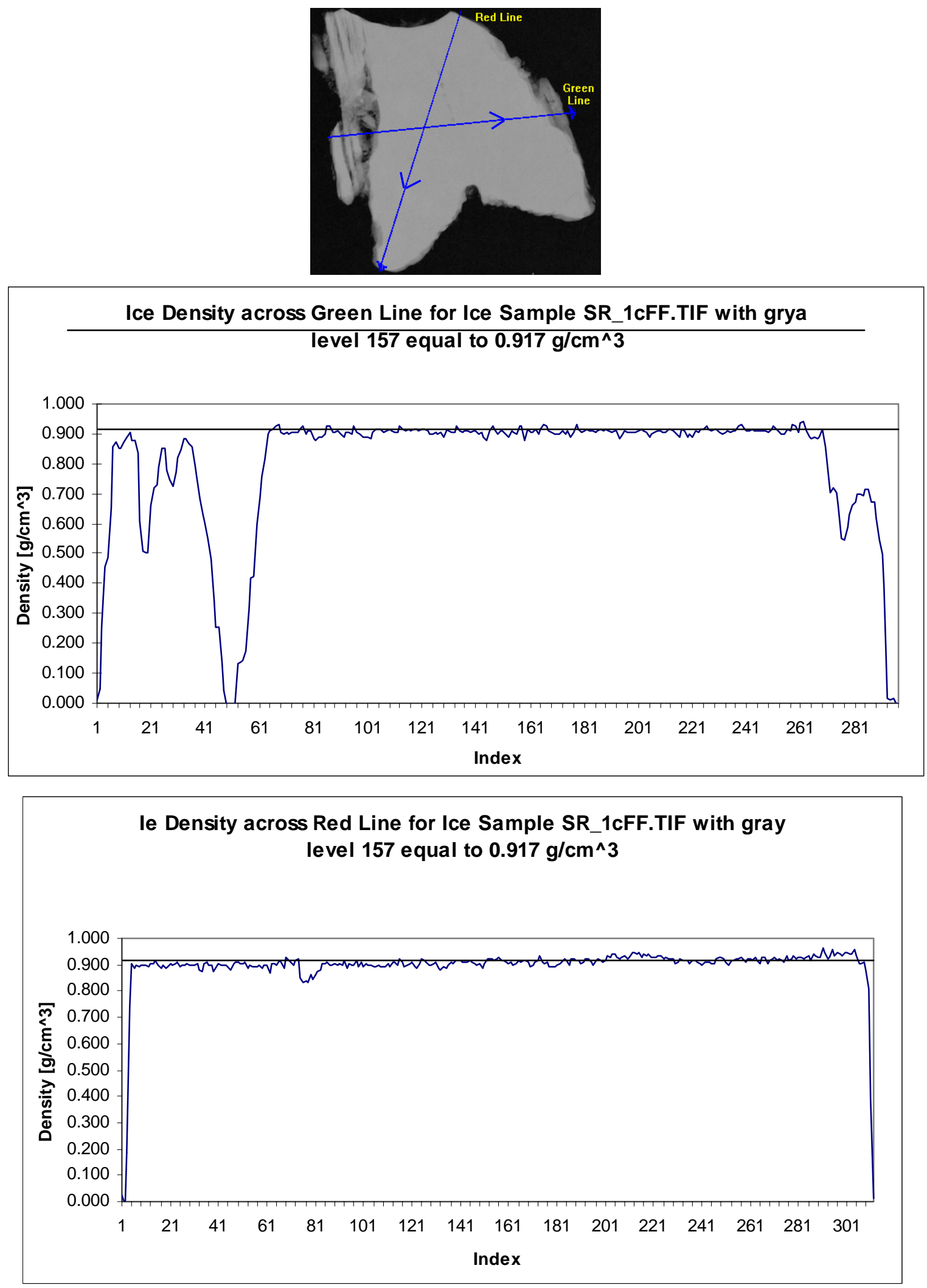

Figure 12. - Sample SR_1cFF.TIF for glaze ice case. V $=150 \mathrm{mph}, \mathrm{LWC}=1.0 \mathrm{~g} / \mathrm{m}^{3}, \mathrm{MVD}=$ $30 \mu \mathrm{m}, \mathrm{T}_{\text {tot }}=12{ }^{\circ} \mathrm{F}, \tau=12$ minutes. 

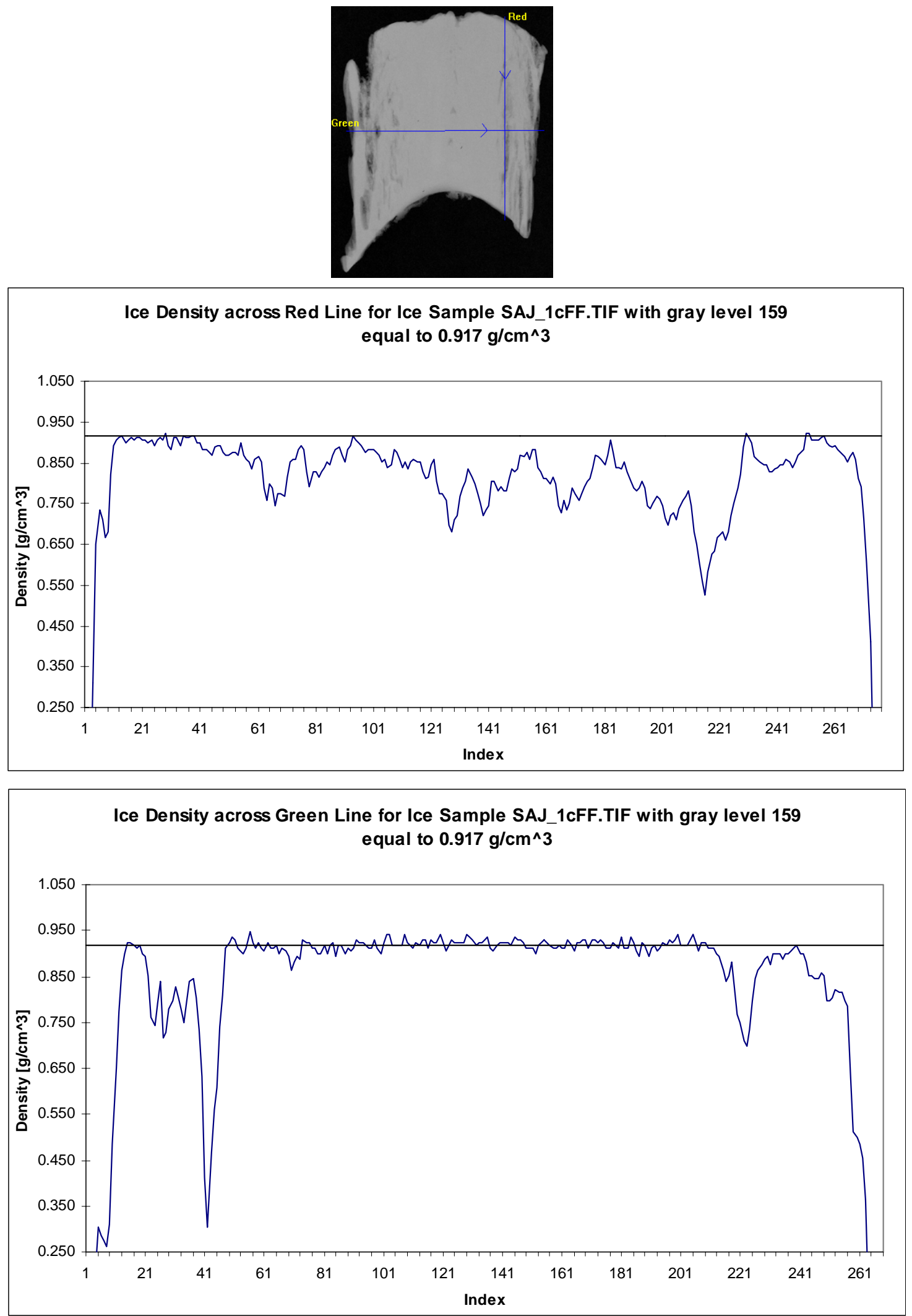

Figure 13.-Sample SAJ_1cFF.TIF for mixed ice case. V $=150 \mathrm{mph}, \mathrm{LWC}=1.0 \mathrm{~g} / \mathrm{m}^{3}, \mathrm{MVD}=$ $20 \mu \mathrm{m}, \mathrm{T}_{\text {tot }}=12{ }^{\circ} \mathrm{F}, \tau=12$ minutes. 

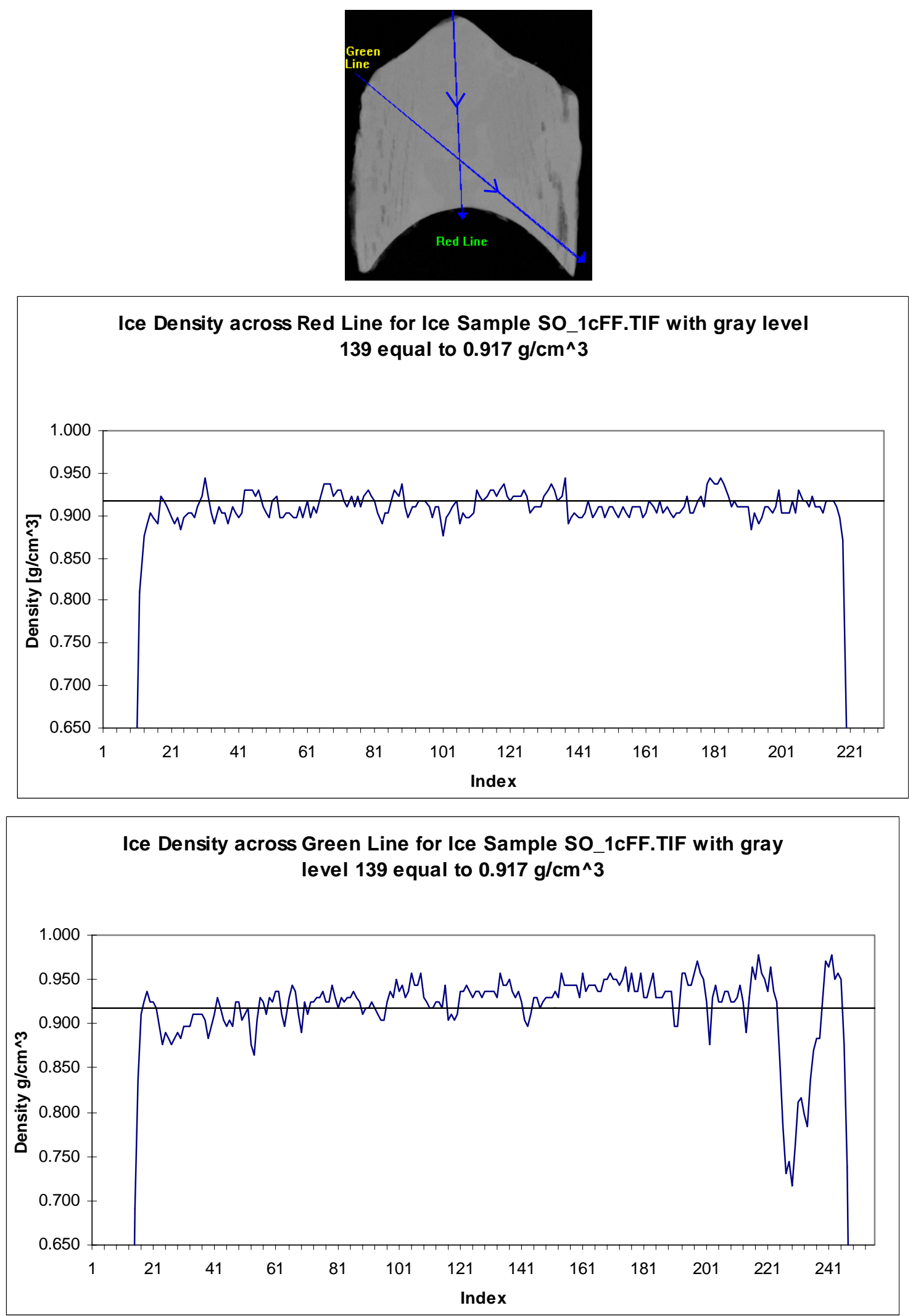

Figure 14. - Sample SO_1cFF.TIF for mixed ice case. V $=150 \mathrm{mph}, \mathrm{LWC}=0.75 \mathrm{~g} / \mathrm{m}^{3}, \mathrm{MVD}=$ $20 \mu \mathrm{m}, \mathrm{T}_{\text {tot }}=12^{\circ} \mathrm{F}, \tau=12$ minutes. 

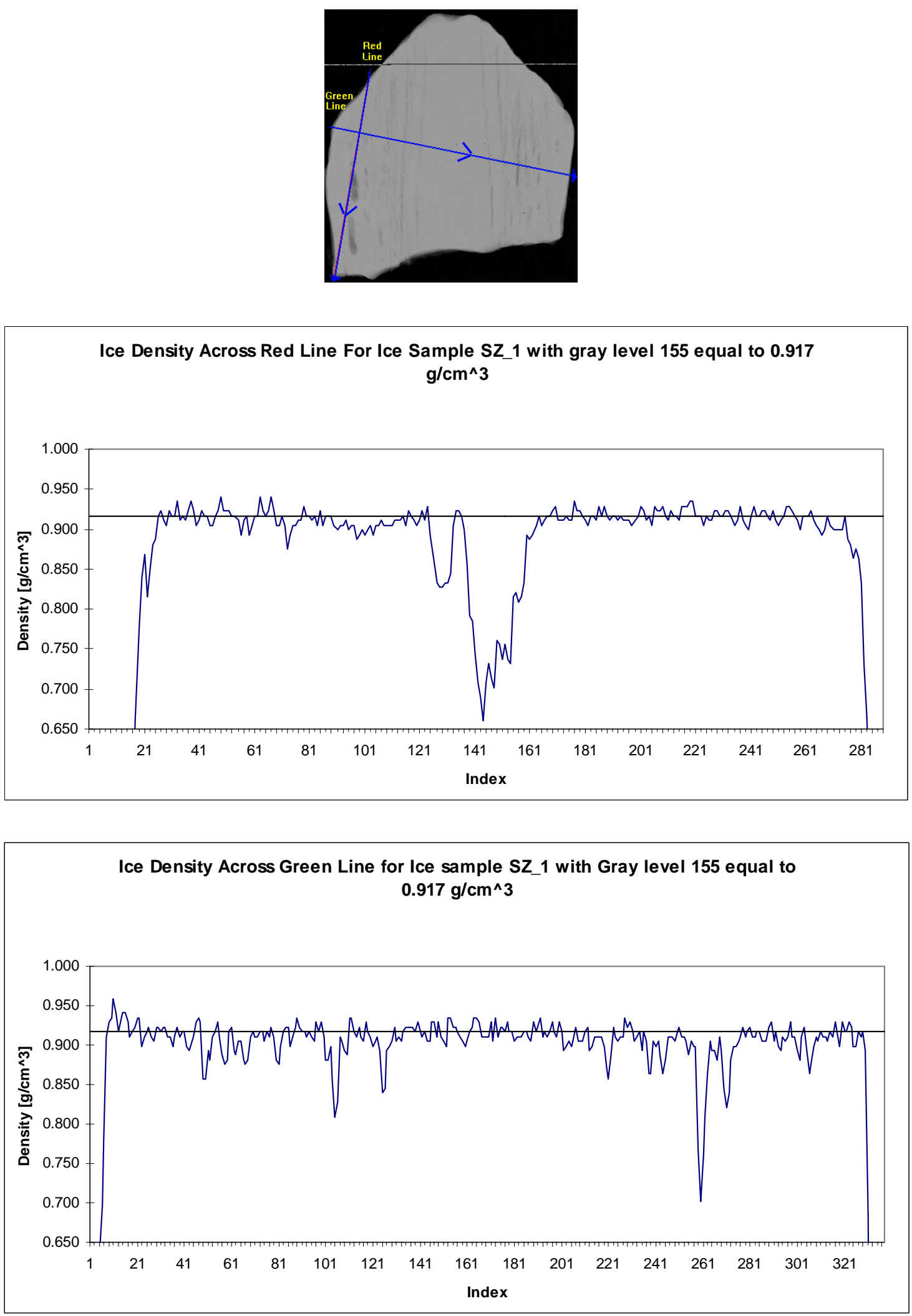

Figure 15. - Sample SZ_1cFF.TIF for mixed ice case. V $=150 \mathrm{mph}, \mathrm{LWC}=1.0 \mathrm{~g} / \mathrm{m}^{3}, \mathrm{MVD}=$ $30 \mu \mathrm{m}, \mathrm{T}_{\text {tot }}=0{ }^{\circ} \mathrm{F}, \tau=12$ minutes. 

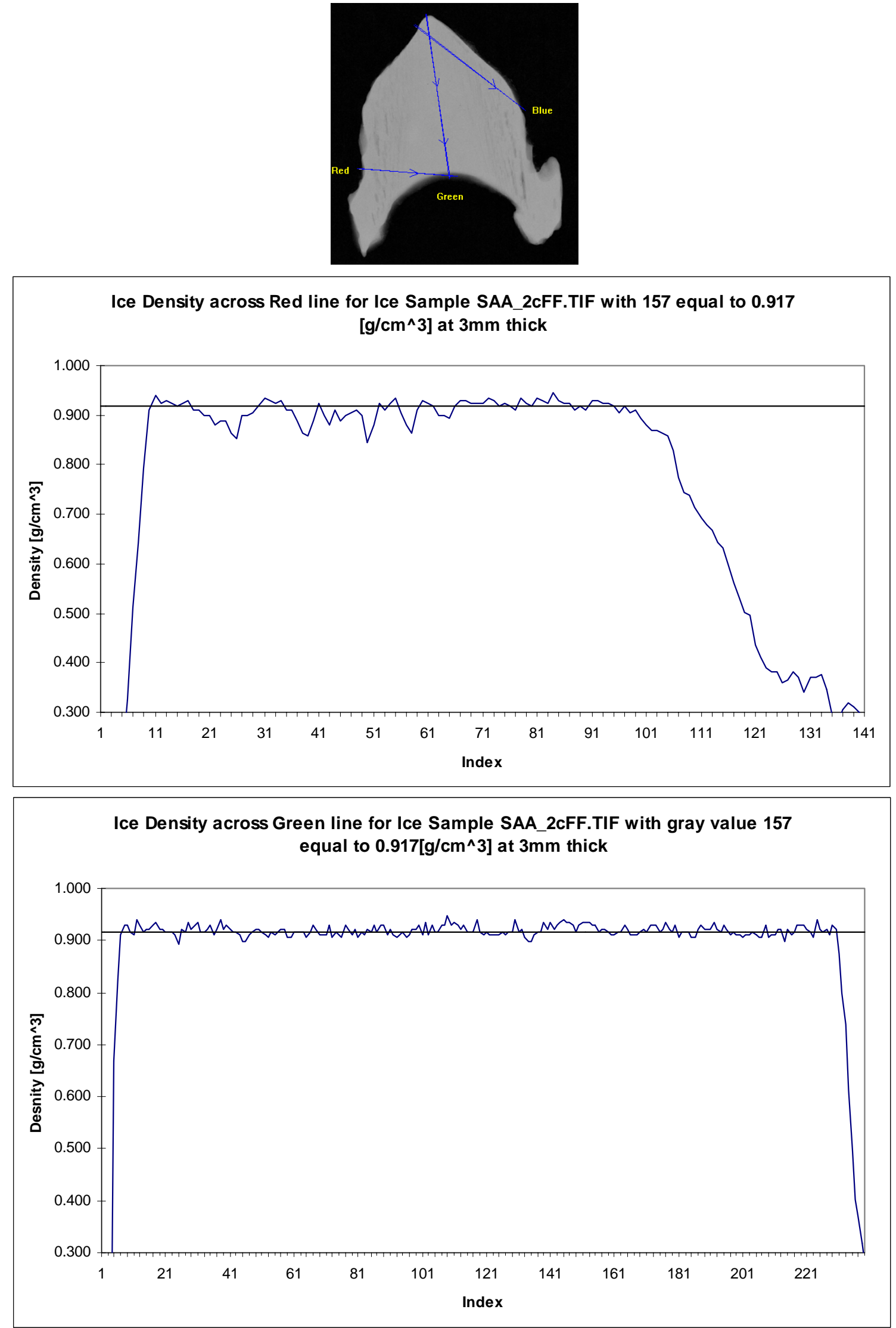

Figure 16.-Sample SAA_2cFF.TIF for rime ice case. No data is presented for the line labeled "blue". $\mathrm{V}=100 \mathrm{mph}, \mathrm{LWC}=1.0 \mathrm{~g} / \mathrm{m}^{3}, \mathrm{MVD}=20 \mu \mathrm{m}, \mathrm{T}_{\mathrm{tot}}=0{ }^{\circ} \mathrm{F}, \tau=12$ minutes. 

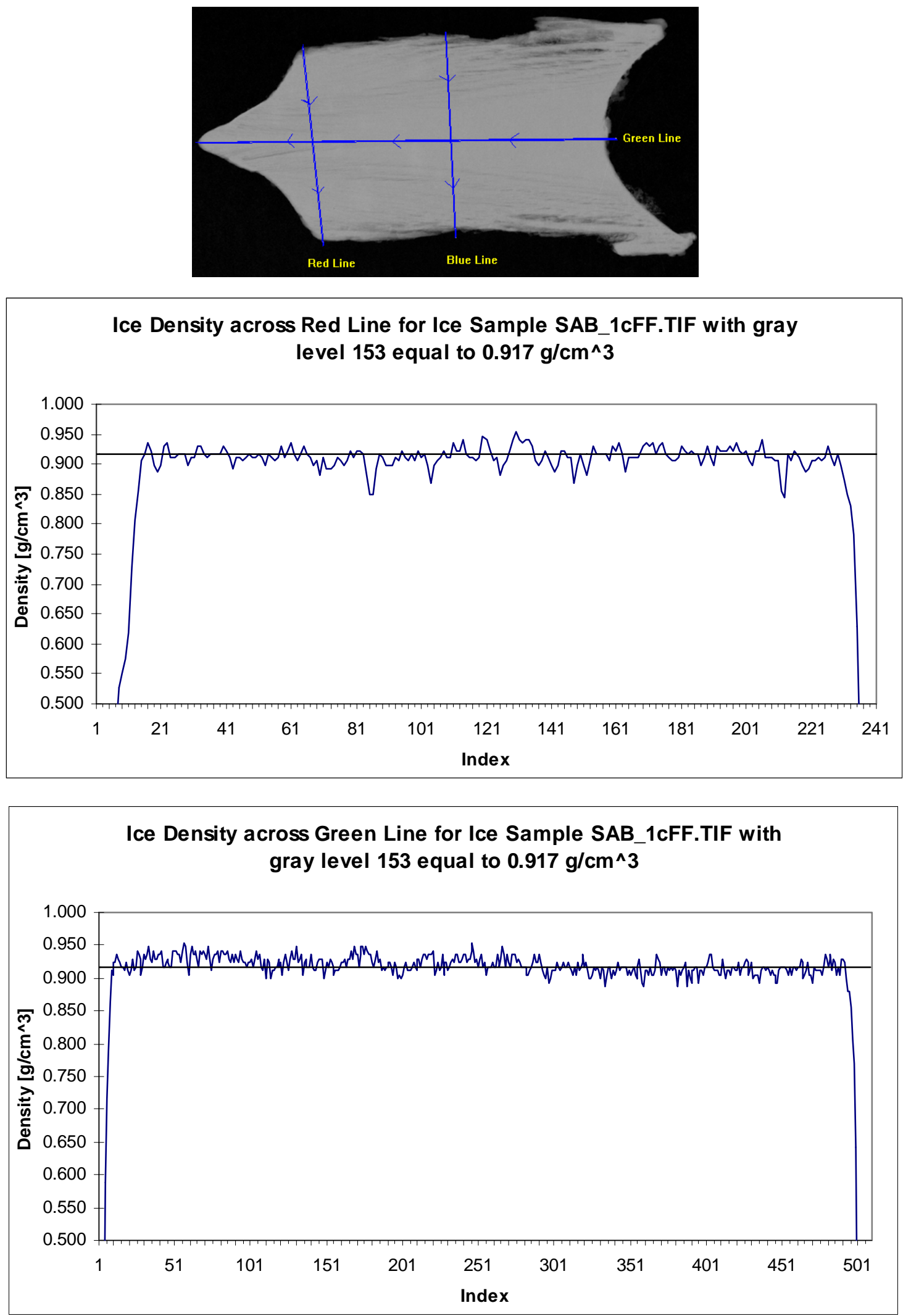

Figure 17.-Sample SAB_1cFF.TIF for rime ice case. No data is presented for the line labeled "blue". $\mathrm{V}=200 \mathrm{mph}, \mathrm{LWC}=1.0 \mathrm{~g} / \mathrm{m}^{3}, \mathrm{MVD}=20 \mu \mathrm{m}, \mathrm{T}_{\text {tot }}=0{ }^{\circ} \mathrm{F}, \tau=12$ minutes. 

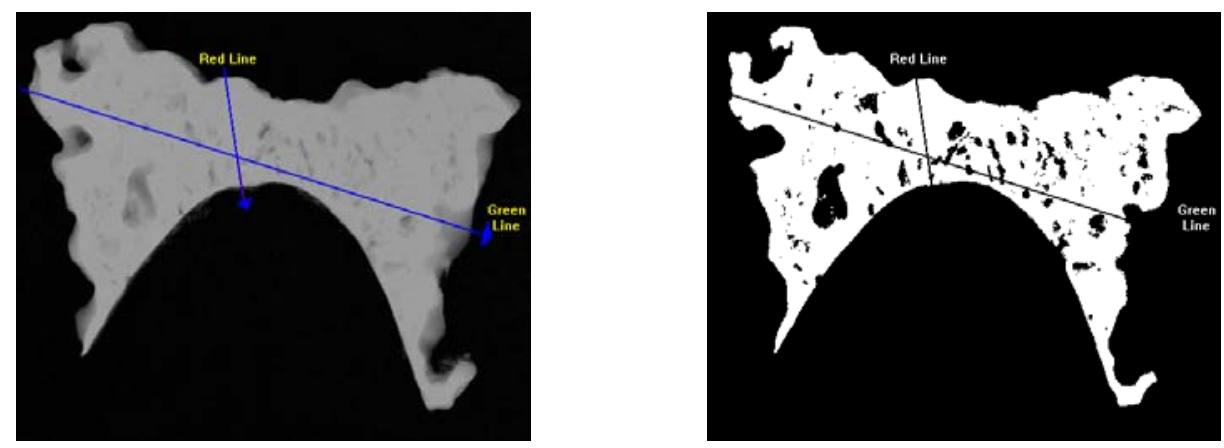

(a) Glaze ice case. Sample SAO_1cFF.TIF

$\mathrm{V}=200 \mathrm{mph}, \mathrm{LWC}=1.25 \mathrm{~g} / \mathrm{m}^{3}, \mathrm{MVD}=20 \mu \mathrm{m}, \mathrm{T}_{\text {tot }}=28{ }^{\circ} \mathrm{F}, \tau=12$ minutes.
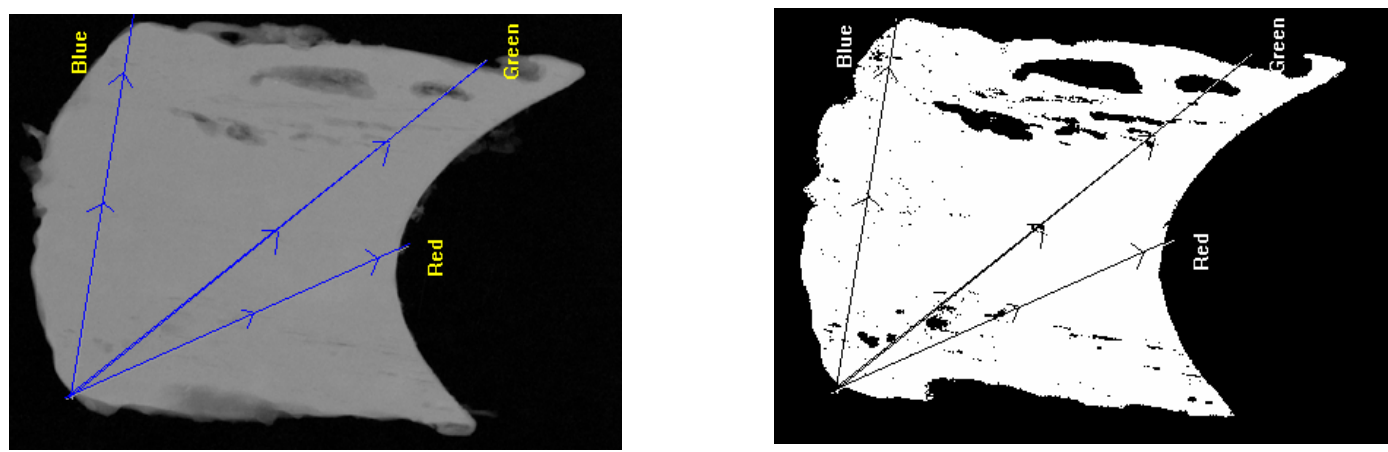

(b) Mixed ice case. Sample SL_1cFF.TIF

$\mathrm{V}=150 \mathrm{mph}, \mathrm{LWC}=1.0 \mathrm{~g} / \mathrm{m}^{3}, \mathrm{MVD}=20 \mu \mathrm{m}, \mathrm{T}_{\text {tot }}=12^{\circ} \mathrm{F}, \tau=12$ minutes.
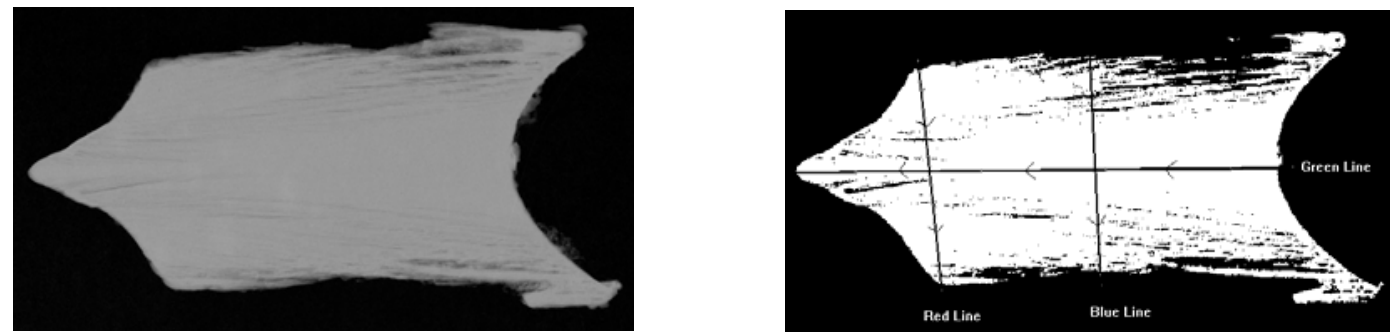

(c) Rime ice case. Sample SAB_1cFF.TIF

$\mathrm{V}=200 \mathrm{mph}, \mathrm{LWC}=1.0 \mathrm{~g} / \mathrm{m}^{3}, \mathrm{MVD}=20 \mu \mathrm{m}, \mathrm{T}_{\text {tot }}=0{ }^{\circ} \mathrm{F}, \tau=12$ minutes.

Figure 18.-Air pockets in glaze, mixed, and rime ice shapes. For each case, the original image (left side) has been enhanced (right side) using Adobe Photoshop to show the presence of air pockets. 


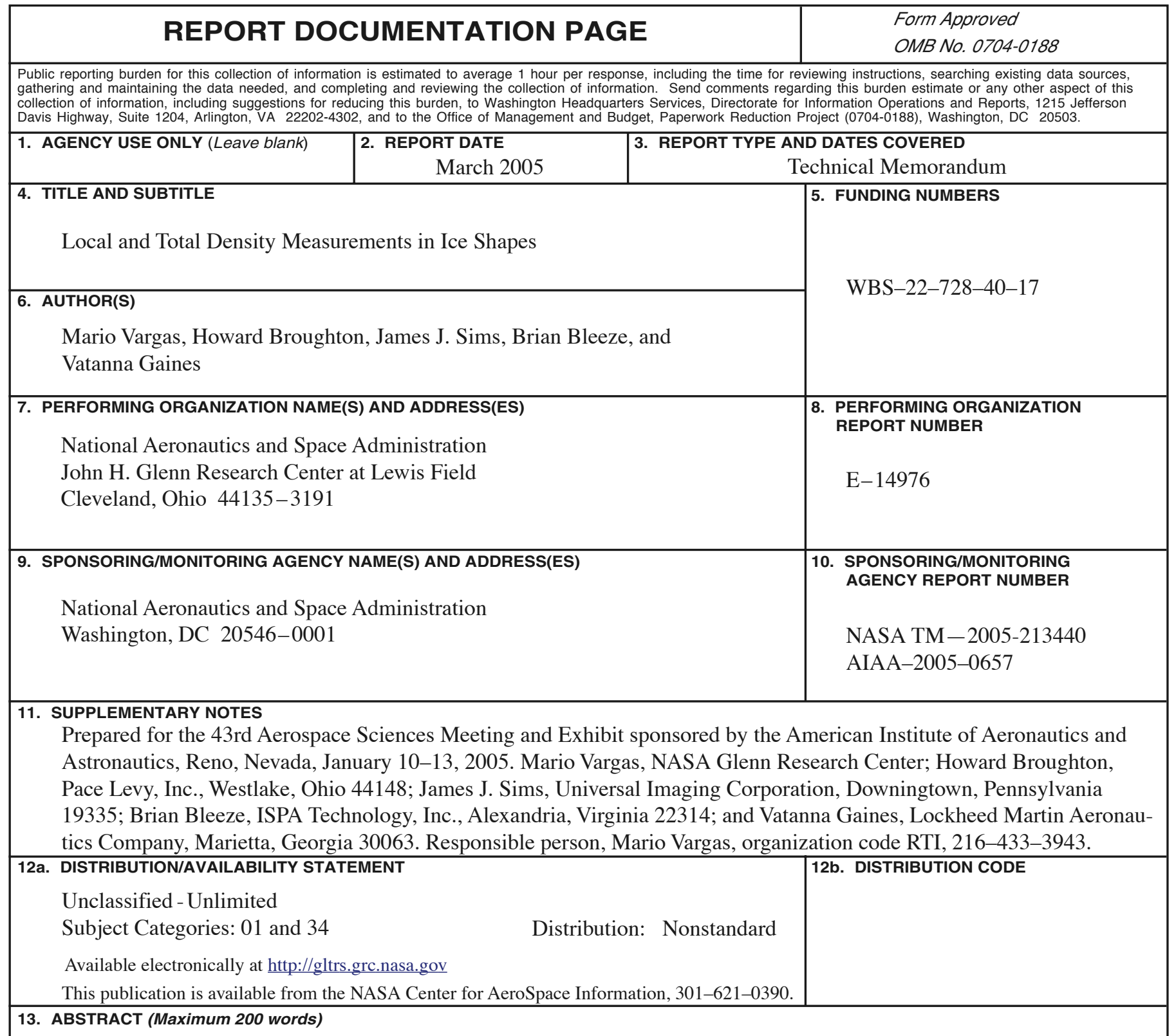

Preliminary measurements of local and total densities inside ice shapes were obtained from ice shapes grown in the NASA Glenn Research Tunnel for a range of glaze ice, rime ice, and mixed phase ice conditions on a NACA 0012 airfoil at $0^{\circ}$ angle of attack. The ice shapes were removed from the airfoil and a slice of ice $3 \mathrm{~mm}$ thick was obtained using a microtome. The resulting samples were then x-rayed to obtain a micro-radiography, the film was digitized, and image processing techniques were used to extract the local and total density values.

\begin{tabular}{|c|c|c|c|}
\hline \multicolumn{3}{|l|}{ 14. SUBJECT TERMS } & 15. NUMBER OF PAGES \\
\hline \multicolumn{3}{|c|}{ Ice formation; Image processing; Radiography } & \begin{tabular}{|l}
30 \\
16.
\end{tabular} \\
\hline $\begin{array}{l}\text { 17. SECURITY CLASSIFICATION } \\
\text { OF REPORT }\end{array}$ & $\begin{array}{l}\text { 18. SECURITY CLASSIFICATION } \\
\text { OF THIS PAGE }\end{array}$ & $\begin{array}{l}\text { 19. SECURITY CLASSIFICATION } \\
\text { OF ABSTRACT }\end{array}$ & 20. LIMITATION OF ABSTRACT \\
\hline Unclassified & Unclassified & Unclassified & \\
\hline
\end{tabular}



